\title{
Role of AMP-activated protein kinase in cross-talk between apoptosis and autophagy in human colon cancer
}

\author{
X Song ${ }^{1}$, S-Y Kim ${ }^{1}$, L Zhang ${ }^{2}$, D Tang ${ }^{1}$, DL Bartlett ${ }^{1}$, YT Kwon ${ }^{3}$ and YJ Lee ${ }^{\star, 1,2}$
}

Unresectable colorectal liver metastases remain a major unresolved issue and more effective novel regimens are urgently needed. While screening synergistic drug combinations for colon cancer therapy, we identified a novel multidrug treatment for colon cancer: chemotherapeutic agent melphalan in combination with proteasome inhibitor bortezomib and mTOR (mammalian target of rapamycin) inhibitor rapamycin. We investigated the mechanisms of synergistic antitumor efficacy during the multidrug treatment. All experiments were performed with highly metastatic human colon cancer CX-1 and HCT116 cells, and selected critical experiments were repeated with human colon cancer stem Tu-22 cells and mouse embryo fibroblast (MEF) cells. We used immunochemical techniques to investigate a cross-talk between apoptosis and autophagy during the multidrug treatment. We observed that melphalan triggered apoptosis, bortezomib induced apoptosis and autophagy, rapamycin caused autophagy and the combinatorial treatment-induced synergistic apoptosis, which was mediated through an increase in caspase activation. We also observed that mitochondrial dysfunction induced by the combination was linked with altered cellular metabolism, which induced adenosine monophosphate-activated protein kinase (AMPK) activation, resulting in Beclin-1 phosphorylated at Ser 93/96. Interestingly, Beclin-1 phosphorylated at Ser 93/96 is sufficient to induce Beclin-1 cleavage by caspase-8, which switches off autophagy to achieve the synergistic induction of apoptosis. Similar results were observed with the essential autophagy gene, autophagy-related protein 7 , -deficient MEF cells. The multidrug treatment-induced Beclin-1 cleavage was abolished in Beclin-1 double-mutant (D133A/D146A) knock-in HCT116 cells, restoring the autophagy-promoting function of Beclin-1 and suppressing the apoptosis induced by the combination therapy. These observations identify a novel mechanism for AMPK-induced apoptosis through interplay between autophagy and apoptosis.

Cell Death and Disease (2014) 5, e1504; doi:10.1038/cddis.2014.463; published online 30 October 2014

Colorectal cancer ranks third in major causes of cancerrelated mortality worldwide, appearing in $\sim 150000$ new cases in the United States annually, and $\sim 20-50 \%$ of colorectal cancer patients display hepatic metastases. ${ }^{1,2}$ Current standard therapies for treating metastatic colon cancer include chemotherapy and biological therapy followed by tumor resection, up front tumor resection followed by systemic therapy, radiofrequency ablation, thermal ablation, selective internal radiation therapy and hyperthermic isolated hepatic perfusion (IHP) therapy. ${ }^{3-7}$ Although these therapies are somewhat effective, more effective novel regimens are still needed to improve the survival of patients with liver metastases from colorectal cancer.

As unresectable liver metastases from colorectal cancer are difficult to treat by single modality, we have spent several years developing a multimodality approach for hyperthermic IHP therapy. We previously investigated the mechanism of the synergy between hyperthermia, biological agents (TNFrelated apoptosis-inducing ligand/mapatumumab) and chemotherapeutic agent (oxaliplatin). ${ }^{8-10}$ However, the clinical grade of those biological agents is no longer available after newly merged companies decided not to produce them. We then investigated potential replacement drugs, which are already Food and Drug Administration (FDA) approved. We screened several FDA-approved drugs including melphalan, chlorquine, bortezomib, carbamazepine, celecoxib, cetuximab and rapamycin using cytoxicity assay. We found that MBR (melphalan+bortezomib+rapamycin) treatment has the best cytotoxic effect on colon cancer cells and also on colon cancer stem cells. Currently, 2807 clinical trials are listed for colon cancer; of these, 225 studies and 195 studies are related to FOLFOX (folinic acid+fluorouracil+oxaliplatin) therapy and

\footnotetext{
${ }^{1}$ Department of Surgery, University of Pittsburgh, Hillman Cancer Center, Pittsburgh, PA 15213, USA; ${ }^{2}$ Department of Pharmacology and Chemical Biology, School of Medicine, University of Pittsburgh, Pittsburgh, PA 15213, USA and ${ }^{3}$ Protein Metabolism Medical Research Center and Department of Biomedical Science, College of Medicine, Seoul National University, Seoul 110-799, South Korea

*Corresponding author: YJ Lee, Department of Surgery, University of Pittsburgh, Hillman Cancer Center, Pittsburgh, PA 15213, USA. Tel: +1 412 623 3268 ; Fax: +1 412623 7709; E-mail: leeyj@upmc.edu

Abbreviations: AICAR, aminoimidazole carboxamide ribonucleotide; AMPK, 5' adenosine monophosphate-activated protein kinase; ATP, adenosine-5'-triphosphate; ATG, autophagy-related protein; BAX, Bcl-2-associated X protein; FDA, Food and Drug Administration; FITC, fluorescein isothiocyanate; IHP, isolated hepatic perfusion; LC3, microtubule-associated protein 1A/1B-light chain 3; mTOR, mammalian target of rapamycin; PARP, poly (ADP-ribose) polymerase; PAGE, polyacrylamide gel electrophoresis; SDS, sodium dodecyl sulfate; TRAIL, TNF-related apoptosis-inducing ligand

Received 30.4.14; revised 20.8.14; accepted 25.8.14; Edited by R Aqeilan
} 
FOLFIRI (folinic acid+fluorouracil+irinotecan) therapy, respectively. There are only seven studies for IHP and, specifically, there is no clinical trial with MBR for hyperthermic IHP therapy.

Apoptosis is a major cytotoxic mechanism of chemotherapy; stress-induced apoptosis often proceeds through the intrinsic pathway where permeabilization of the mitochondrial outer membrane releases cytochrome $c$ and activates the caspase cascade. ${ }^{11,12}$ Melphalan hydrochloride (trade name Alkeran), which is commonly used in IHP, leads to double-stranded DNA breaks and subsequent cell death through a caspasemediated, apoptotic pathway. ${ }^{13,14}$

Bortezomib, the first clinically available proteasome inhibitor, possesses antitumor activity in a variety of human cancers and is often used in the treatment of hematological malignancies. It can induce both proapoptotic effects, including the induction of Bik, Bim and Noxa proteins, and antiapoptotic effects, including the accumulation of $\mathrm{Mcl}-1$ and HSP70, as well as autophagic formation. ${ }^{15-17}$

mTOR (mammalian target of rapamycin) is known to be well conserved and ubiquitously expressed in endothelial cells and is involved in cell energy metabolism, cell growth, apoptosis and autophagy. Several human cancers display mTOR hyperactivation, thus making mTOR an attractive target in cancer therapy. ${ }^{18}$ Sirolimus, known as rapamycin, an mTOR inhibitor, has relatively low cytotoxic activity. Better therapeutic outcomes should be obtained by using rapamycin in combination with other anticancer agents. ${ }^{19,20}$ In this study, we observed that melphalan triggered apoptosis, bortezomib induced both apoptosis and autophagy, rapamycin caused autophagy and the combinatorial treatment promoted mitochondrial dysfunction and synergistic apoptosis.

Hallmarks of cancer cells include uncontrolled growth, evasion of apoptosis, immortality, ability to invade other tissues and altered cellular metabolism. ${ }^{21}$ In our study, we investigated the effect of multidrug treatment on cellular metabolism. This study revealed that the combinatorial treatment altered cellular metabolism and induced energy sensor AMP-activated protein kinase (AMPK) activation at two stages in the process, resulting in Beclin-1 phosphorylation and autophagy starting with the early stage and Beclin-1 cleavage by caspase- 8 and apoptosis concurrent with the late stage. Our observations provided evidence that AMPK has an important role in cross-talk between autophagy and apoptosis.

\section{Results}

MBR synergistically induced cytotoxicity and apoptosis. To investigate the effect on cell viability of the application of MBR, human colorectal carcinoma HCT116 and CX-1 cells were treated with a combination of $10 \mu \mathrm{g} / \mathrm{ml}$ melphalan, along with $50 \mathrm{nM}$ bortezomib and/or $2.5 \mu \mathrm{g} / \mathrm{ml}$ rapamycin for $24 \mathrm{~h}$. Cell viability was determined by 3-(4,5-dimethylthiazol-2-yl)5-(3-carboxymethoxyphenyl)-2-(4-sulfophenyl)-2 $\mathrm{H}$-tetrazolium (MTS) assay. As shown in Figures 1a and b, synergistic effect was observed in MBR compared with any single treatment or bitreatment in both cell lines $(P<0.01)$. Our observation was confirmed by combination index $(\mathrm{Cl})$ analysis; $\mathrm{Cl}$ values were $<1$ (Table 1). In Figure 1c, apoptotic cells detected by Annexin V/PI assay were observed in the upper right quadrant of each plot. Our data clearly show that treatment with MBR enhanced synergistic induction of apoptotic death. These synergistic effects were due to an increased activation of caspases, and thus, the hallmark of apoptosis, poly (ADP-ribose) polymerase (PARP) cleavage (Figures 1d and e). Similar results were observed in human colon cancer stem Tu-22 cells (Figure 1f).

MBR-induced mitochondrial dysfunction and AMPK activation. Stress-induced apoptosis often proceeds through the intrinsic pathway mediated by THE mitochondria. In Figures $2 a$ and $b$, the upper left quadrant of each plot displays cells with intact mitochondrial membrane potential, whereas the lower right quadrant displays cells with impaired mitochondrial membrane potential. A significant shift occurred to the lower right part of the quadrants in the treatment with MBR. Figure $2 \mathrm{c}$ indicates that more cytochrome $c$ was released during multidrug treatment. We then assessed the ATP production as the mitochondria are known to have an important role in providing overall cellular energy supply. ATP production was markedly decreased during the treatment with MBR in HCT116 cells (Figure 2d) and CX-1 cells (data not shown). Figure 2 e shows that MBR induced a large amount of phosphorylation (activation) of AMPK. We then investigated whether $\mathrm{Bcl}-2$-associated $\mathrm{X}$ protein (Bax) was involved in the combinatorial treatment-induced apoptosis. Data from Figure $2 f$ clearly demonstrates that MBRinduced apoptosis and caspase activation were effectively suppressed in Bax-deficient cells, indicating that the synergy of MBR-associated apoptosis is partially mediated through Bax. Interestingly, AMPK activation was also decreased in HCT116 $\mathrm{Bax}^{-1-}$ cells, implying that Bax contributes to AMPK activation. The hallmark of autophagy, microtubuleassociated protein 1A/1B-light chain 3 (LC3)-II, increased markedly in bortezomib-treated cells and mildly in rapamycintreated cells but no significant increase with melphalan treatment. Notably, there was a significant decrease of LC3II in the treatment of MBR compared with that of bortezomib alone. Interestingly, LC3-II was increased in the treatment of MBR in HCT116 $\mathrm{Bax}^{-/-}$cells compared with that of HCT116 $\mathrm{Bax}^{+/+}$cells, indicating that autophagy was increased in the apoptosis-suppressed cells (Figure 2f). These results indicate a cross-talk between autophagy and apoptosis during treatment with MBR. Figure $2 \mathrm{~g}$ shows that cytotoxicity was significantly decreased in HCT116 $\mathrm{Bax}^{-/-}$compared with HCT116 $\mathrm{Bax}^{+/+}(P<0.01)$.

Interplay between autophagy and apoptosis during treatment with MBR. To further investigate a relationship between apoptosis and autophagy during treatment with MBR, we examined autophagy using as an autophagyspecific marker both processing of LC3-I into LC3-II using immunoblot assay and also green fluorescent protein (GFP)LC3 puncta formation using confocal microscopy. We observed that LC3-II (Figures $3 a$ and b) and LC3 puncta formation (Figure 3c) increased significantly in bortezomib alone or in combination with melphalan or rapamycin. However, MBR treatment suppressed LC3-II or LC3 puncta formation compared with bortezomib alone. It is known that 
a

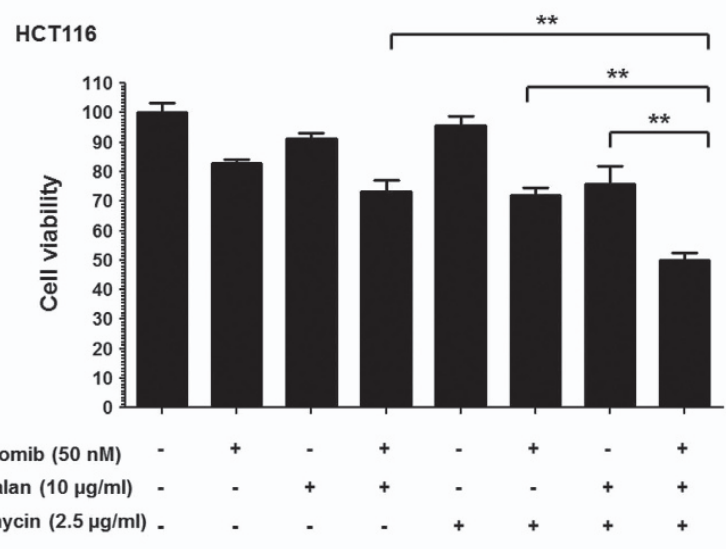

C

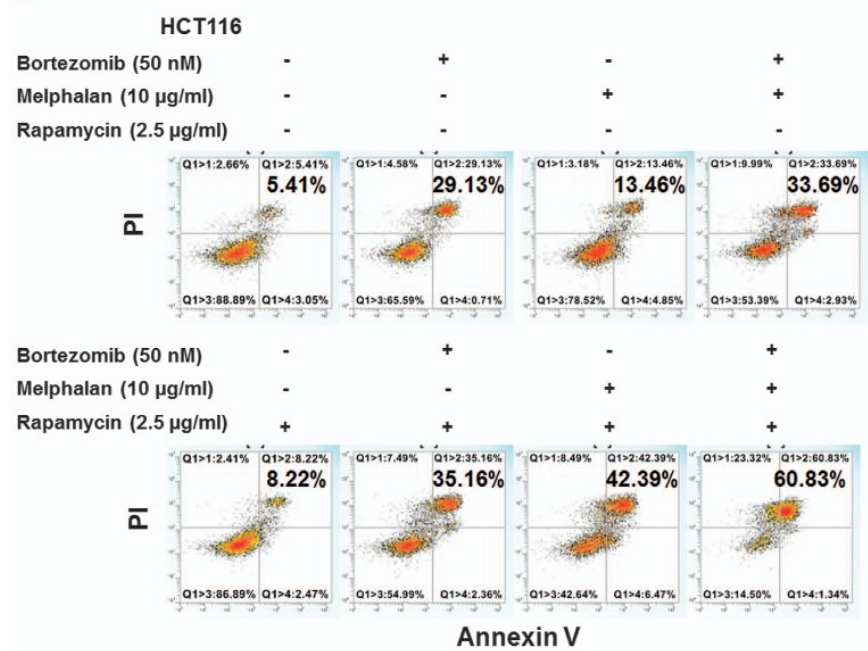

e

CX-1

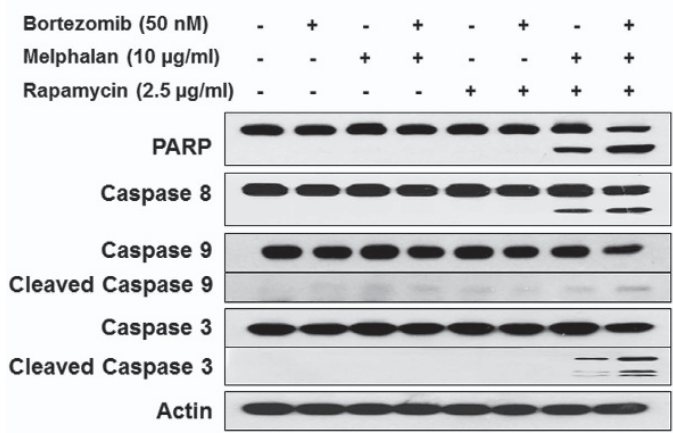

b

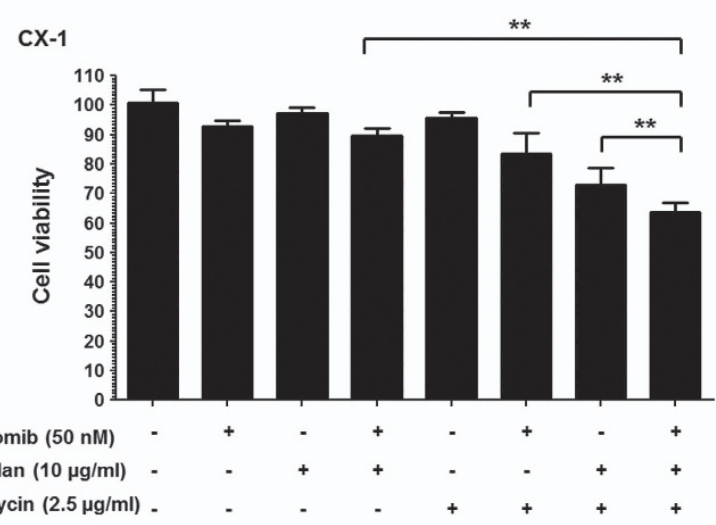

d

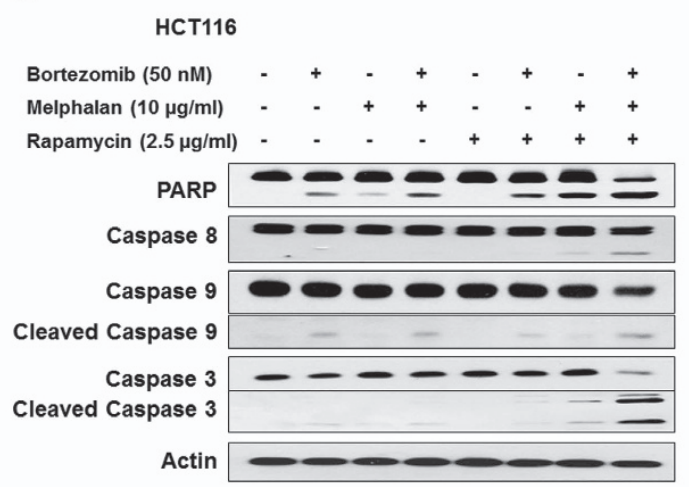

f

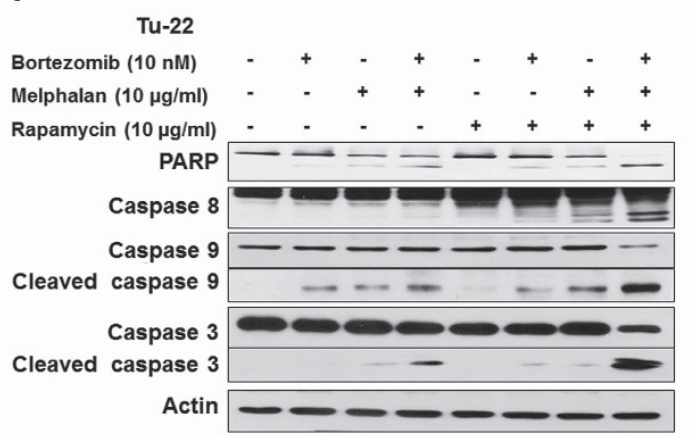

Figure 1 MBR induced cytotoxicity and apoptosis. (a and $\mathbf{b})$ HCT116 (a) and CX-1 (b) cells were treated with MBR for $24 \mathrm{~h}$. Cell viability was analyzed by MTS assay. Error bars represent S.D. from triplicate experiments. ${ }^{* \star} P<0.01$ represents a statistically significant difference. (c) HCT116 cells were treated with MBR for $24 \mathrm{~h}$ and cells were stained with fluorescein isothiocyanate (FITC)-Annexin V and PI. Apoptosis was detected by the flow cytometric assay. (d-f) After treatment, the cleavage of caspase-8, caspase-9, caspase-3 and PARP was detected by immunoblotting in HCT116 (d), CX-1 (e) and Tu-22 (f) cells. Actin was used to confirm the equal amount of proteins loaded in each lane

the classical autophagy pathway is dependent on Beclin-1, autophagy-related protein 7 (ATG7), and so on. ${ }^{22}$ Figure $3 d$ shows that MBR treatment-induced apoptosis was enhanced in mouse embryo fibroblast (MEF) ATG $7^{-1-}$ cells. Similar results were observed by MTS assay (Figure $3 e$ ). These results suggest that inhibition of autophagy enhances multidrug-induced apoptosis.
The role of AMPK in MBR-induced apoptosis. To further investigate a cross-talk between autophagy and apoptosis, we hypothesized that enhancement of MBR-induced apoptosis is mediated through the activation of AMPK. To test this hypothesis, we added an AMPK inhibitor, compound $\mathrm{C}$, in the absence or presence of MBR. Figures $4 \mathrm{a}$ and $\mathrm{b}$ show that MBR-induced apoptosis was partially suppressed 
Table 1 Combination index for melphalan in combination with bortezomib and rapamycin $^{\mathrm{a}}$

\begin{tabular}{|c|c|c|c|c|}
\hline \multicolumn{3}{|c|}{ Combination therapy } & \multicolumn{2}{|c|}{ Combination index } \\
\hline $\begin{array}{l}\text { Melphalan } \\
(\mu \mathrm{g} / \mathrm{ml})\end{array}$ & $\begin{array}{l}\text { Bortezomib } \\
\text { (nM) }\end{array}$ & $\begin{array}{c}\text { Rapamycin } \\
(\mu \mathrm{g} / \mathrm{ml})\end{array}$ & HCT116 & $C X-1$ \\
\hline $\begin{array}{l}10 \\
20 \\
40\end{array}$ & $\begin{array}{r}50 \\
100 \\
200\end{array}$ & $\begin{array}{l}2.5 \\
5 \\
10\end{array}$ & $\begin{array}{l}0.33 \\
0.35 \\
0.49\end{array}$ & $\begin{array}{l}0.52 \\
0.80 \\
0.95\end{array}$ \\
\hline
\end{tabular}

${ }^{\mathrm{a} C}$ Calculated by Compusyn software for HCT116 and CX-1 colon cancer cells

by the addition of compound $\mathrm{C}$, inhibiting the activation of AMPK- $a$. This observation was confirmed by knocking down the expression of AMPK-a. Figure 4c shows that a combination of AMPK- $a 1$ and AMPK- $a 2$ small interfering RNA (siRNA) downregulated AMPK- $a$ expression level and partially suppressed MBR-induced apoptosis, which was consistent with the effects of compound $C$. Our results suggest that MBRinduced AMPK activation has an important role in the crosstalk between autophagy and apoptosis. To further investigate the role of AMPK activators metformin and AICAR (aminoimidazole carboxamide ribonucleotide) in MBR-induced cytotoxicity, cells were treated with metformin/AICAR in the absence or presence of MBR. As shown in Figure 4d, metformin alone did not affect CX-1 cell viability. However, MBR-induced cytotoxicity was significantly enhanced in the presence of $20 \mathrm{mM}$ metformin. Similar results were observed in HCT116 cells (Figure $4 \mathrm{e}$ ). Figures $4 \mathrm{f}$ and $\mathrm{g}$ show that AICAR alone did not affect cell viability in CX-1 and HCT116 cells but MBR-induced cytotoxicity was enhanced in the presence of AICAR.

\footnotetext{
AMPK activation-induced Beclin-1 phosphorylation at Ser 93/96 and Beclin-1 cleavage. To examine the role of AMPK in the cross-talk between autophagy and apoptosis, we further investigated AMPK downstream molecules. Recently, AMPK was reported to phosphorylate Beclin-1 at Ser 91/94 for mouse or Ser 93/96 for human upon glucose starvation. ${ }^{23}$ C-terminal fragment of Beclin-1 localizes at the mitochondria, inducing cytochrome $c$ release and thus enhancing the apoptosis. ${ }^{24}$ We observed Beclin-1 phosphorylation at Ser 93/96 in HCT116 and CX-1 cells (Figures 5a and b), as well as Beclin-1 cleavage in HCT116 cells (Figure 5c), during the treatment with MBR. Similar results were observed in Tu-22 cells (Figure $5 d$ ). We also observed that AMPK inhibitor, compound $\mathrm{C}$, inhibited Beclin-1 phosphorylation at Ser 93/96 and Beclin-1 cleavage in both cell lines (Figures $5 \mathrm{e}$ and $\mathrm{f}$ ). Figure $5 \mathrm{~g}$ shows that $1 \mathrm{mM}$ AICAR alone, which activated AMPK, did not induce apoptosis in CX-1 and HCT116 cells. However, AICAR enhanced MBRinduced apoptosis. We also observed that MBR-induced PARP cleavage, Beclin-1 phosphorylation at Ser 93/96 and Beclin-1 cleavage were enhanced in the presence of AICAR in both cell lines. AICAR alone increased the level of LC3-II (autophagy). However, a combinatorial treatment of MBR and AICAR reduced MBR-induced LC3-II. These results suggest a strong correlation between AMPK activation, Beclin-1
}

cleavage and switching the mode of cell death from autophagy to apoptosis.

The kinetics of AMPK- $a$ activation and Beclin-1 phosphorylation and cleavage in the treatment of MBR. Next, we examined the kinetics of MBR-induced apoptosis. As shown in Figures $6 a$ and $b$, MBR-induced apoptosis was increased as time progressed. In CX-1 cells, AMPK was phosphorylated (activated) very early at $1 \mathrm{~h}$ and then decreased. Notably, activation of AMPK was increased again at around $16 \mathrm{~h}$ in a sustained manner. Beclin-1 phosphorylation at Ser 93/96 was markedly increased after $3 \mathrm{~h}$. Beclin-1 cleavage increased after $12 \mathrm{~h}$ when apoptosis occurred and then apoptosis was significantly increased. We also monitored autophagy in CX-1 cells after MBR treatment, using as an autophagy-specific marker processing of LC3-I into LC3-II. Interestingly, during the first $16 \mathrm{~h}$, MBR treatment co-occurred with increased autophagy indicated by increased LC3-II levels. But then, reduced levels of LC3-II were observed at $24 \mathrm{~h}$ after treatment, implying that once caspases were fully activated, autophagy levels were diminished. Similar results were obtained in HCT116 cells, which were more sensitive towards the treatment of MBR compared with CX-1 cells (Figure 6b). To further test the differential role of AMPK activation at different stage, we used compound $\mathrm{C}$ to inhibit transiently AMPK at early stage (from 0 to $4 \mathrm{~h}$ and washed at $4 \mathrm{~h}$ with phosphatebuffered saline) and late stage (from 10 to $24 \mathrm{~h}$ ) separately. As shown in Figures $6 c$ and $d$, we observed that inhibiting AMPK at early time point enhanced MBR-induced apoptosis, whereas inhibiting AMPK at late time point abolished MBR-induced apoptosis in CX-1 and HCT116 cells.

We further examined the kinetics of autophagy during treatment with MBR; GFP-LC3 puncta formation was investigated. Figures $6 e$ and $f$ show that LC3 puncta formation was detected at $3 \mathrm{~h}$, and increased until $16 \mathrm{~h}$ and then decreased $\sim 2$-fold at $24 \mathrm{~h}$ compared with that of $16 \mathrm{~h}$ of MBR treatment. Moreover, Figure $6 \mathrm{~g}$ shows that PARP cleavage, AMPK activation and Beclin-1 phosphorylation at Ser 93/96, as well as Beclin-1 cleavage, consistently increased even at $36 \mathrm{~h}$. We also observed that LC3-II was markedly decreased at 28 and $36 \mathrm{~h}$. These data suggest that early AMPK activation-induced Beclin-1 phosphorylation and resulted in autophagy, whereas sustained late AMPK activation co-occurring with the activation of caspases induced Beclin-1 cleavage, enhancing apoptotic cell death.

Beclin-1 phosphorylation at Ser 91/94 is sufficient to induce Beclin-1 cleavage and thus contributes to the synergistic induction of apoptosis. To evaluate the effect of Beclin-1 phosphorylation at Ser 91/94 on its cleavage, we transiently transfected HCT116 cells with empty vector (pcDNA), wild-type murine Beclin-1, murine Beclin-1 S91/94A (residues 91 and 94 serine were replaced by alanine: dominant-negative mutant) and murine Beclin-1 S91/94D (residues 91 and 94 serine were replaced by aspartic acid: dominant-positive mutant) and then treated with MBR for $24 \mathrm{~h}$. As shown in Figure 7a, phosphorylation of wild-type murine Beclin-1, but not Beclin-1 S91/94A or Beclin-1 S91/94D, was elevated by treatment with MBR. Interestingly, Beclin-1 S91/94A reduced MBR-induced PARP cleavage and 
cell death (Figures $7 a$ and $b$ ), indicating that Beclin-1 phosphorylation at Ser $91 / 94$ is a prerequisite for Beclin-1 cleavage.
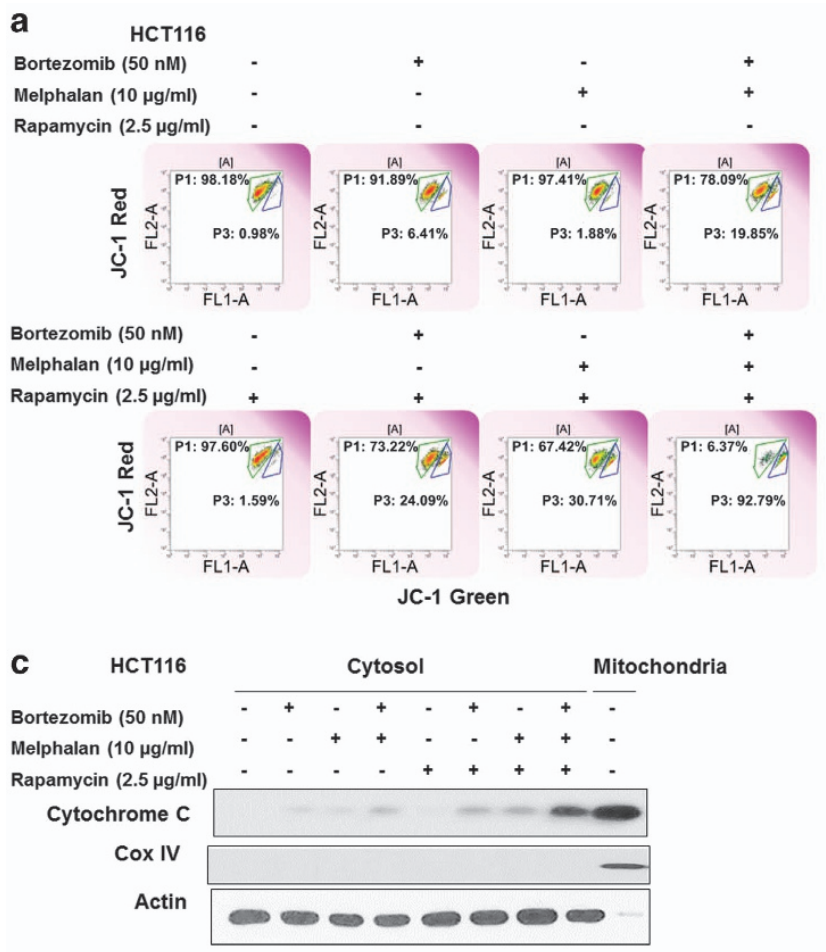

e

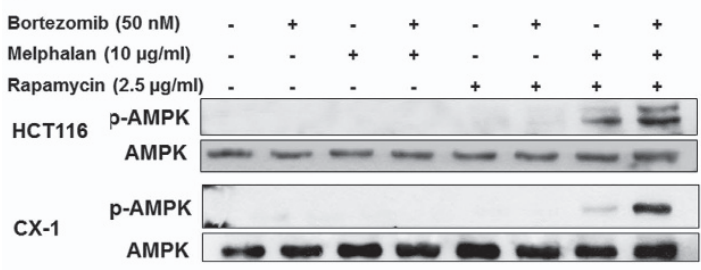

f

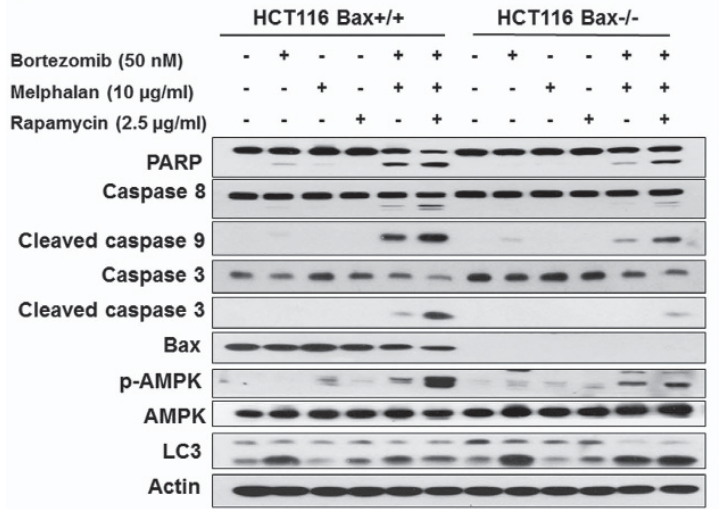

Cleavage of Beclin-1 occurred with caspase activation. As caspase activation occurs during apoptotic signaling, we investigated if Beclin-1 and caspases bind with each other and

b

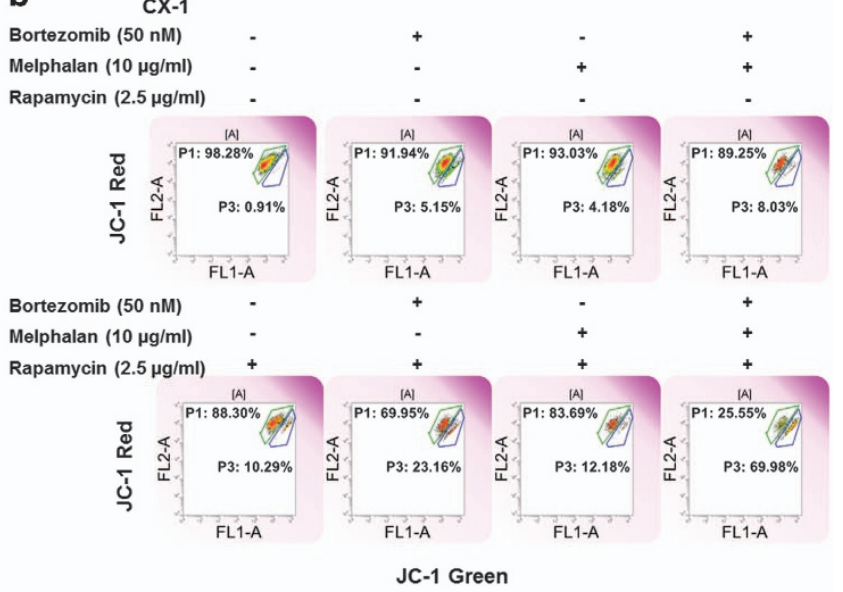

d

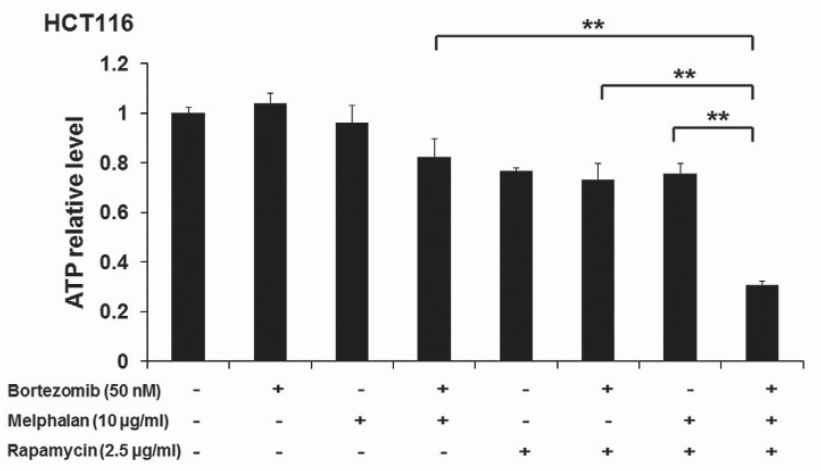

g

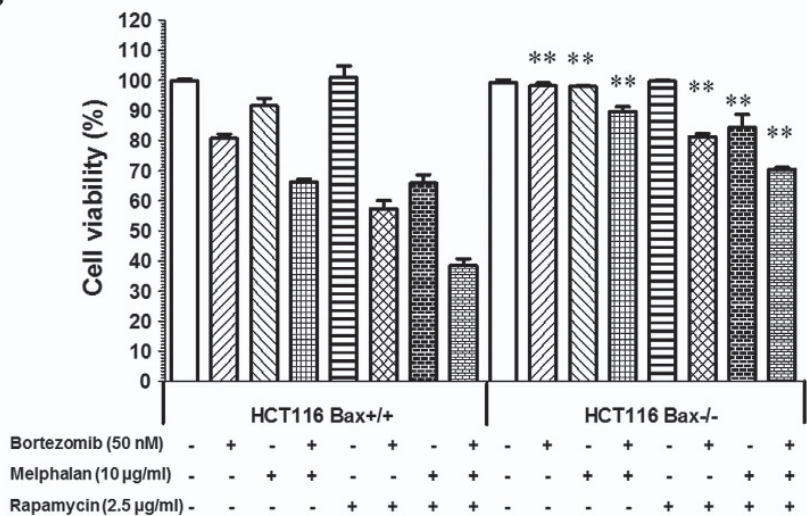

Figure 2 MBR-induced mitochondrial dysfunction and AMPK activation. (a and b) HCT116 (a) and CX-1 (b) cells were treated with MBR for $24 \mathrm{~h}$, stained with JC-1 mitochondrial membrane potential detection kit and analyzed by flow cytometry. (c) After treatment, cytochrome $c$ release into the cytosol was determined by immunoblotting for cytochrome $c$ in the cytosolic fraction of HCT116 cells. Mitochondrial fraction was used as the control. Cox IV was used as a mitochondrial marker and actin as a cytosolic marker. (d) After treatment, ATP levels were assessed by using an ATP Assay Kit (Perkin-Elmer, Akron, OH, USA) in HCT116 cells. Data represent relative ATP levels, with control cells set as 100\% (mean \pm S.D., $\left.n=3,{ }^{* \star} P<0.01\right)$. (e) After treatment, the activation of AMPK- $\alpha$ was detected by immunoblotting in HCT116 and CX-1 cells. (f) Parental HCT116 (HCT116 Bax ${ }^{+/+}$) and Bax-knockout HCT116 Bax $^{-1-}$ cells were treated with MBR for $24 \mathrm{~h}$ and immunoblotted with anti-PARP, anti-caspase-8, anti-caspase-9, anti-caspase-3, anti-phospho-AMPK- $\alpha$, anti-AMPK- $\alpha$ or anti-LC3 antibody. Actin was used to confirm the equal amount of proteins loaded in each lane. (g) HCT116 Bax ${ }^{+/+}$and Bax ${ }^{-1-}$ cells were treated with MBR for $24 \mathrm{~h}$. Cell viability was analyzed by MTS assay. Error bars represent S.D. from triplicate experiments. ${ }^{*} P<0.01$ represents a statistically significant difference 


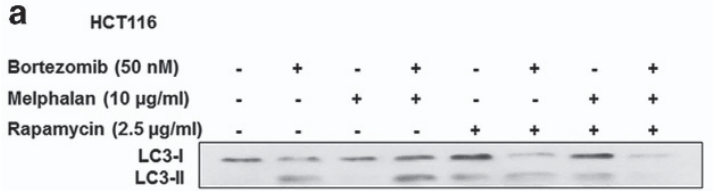

b cx-1

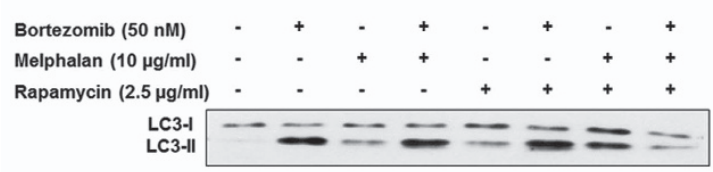

C

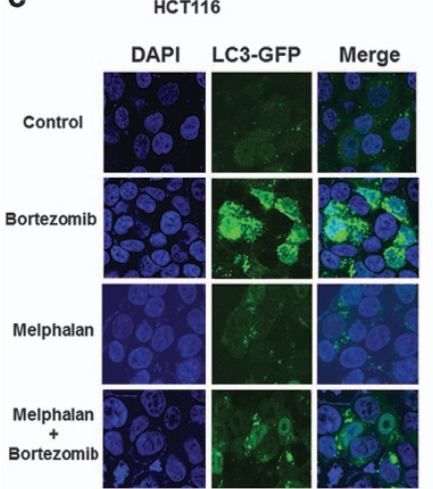

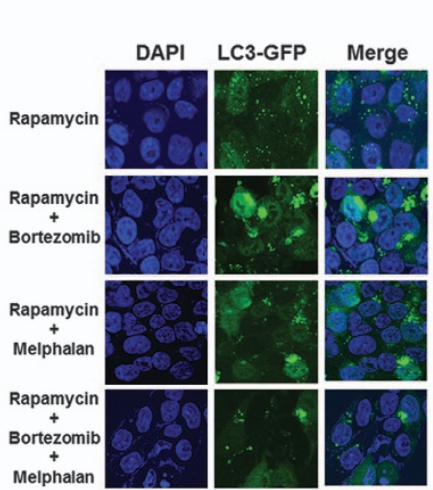

d

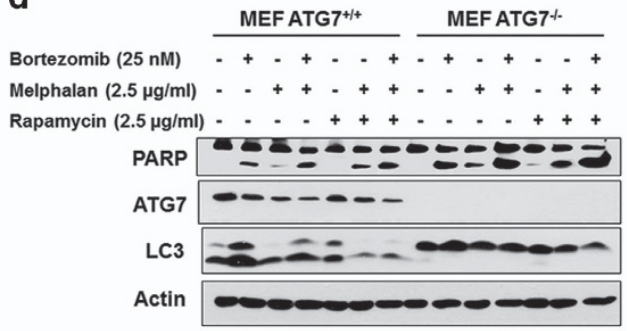

e

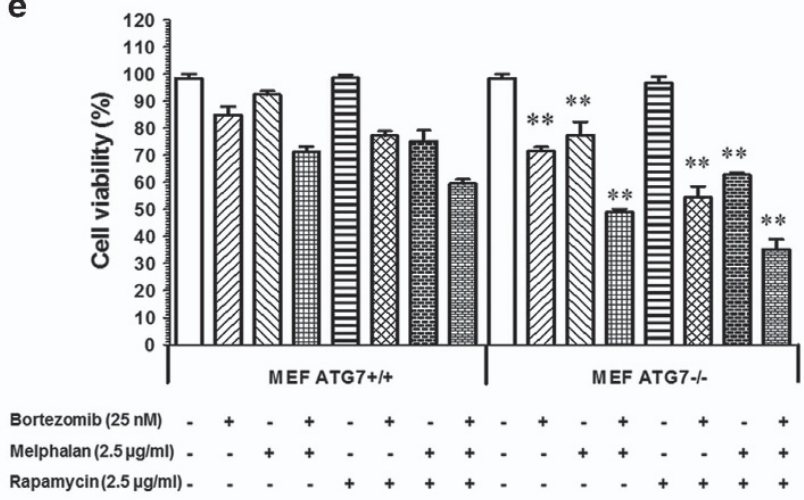

Figure 3 Interplay between autophagy and apoptosis during treatment with MBR. HCT116 (a) and CX-1 (b) cells were treated with MBR for 24 h, and LC3-I and LC3-II were detected by immunoblotting. (c) LC3 puncta formation was examined using confocal microscopy in HCT116 cells. (d) MEF ATG7 ${ }^{+/+}$and MEF ATG ${ }^{-1-}$ cells were treated with MBR for $24 \mathrm{~h}$, and PARP, ATG7 and LC3 were detected by immunoblotting. Actin was used to confirm the equal amount of proteins loaded in each lane. (e) MEF ATG7 $7^{+/+}$and MEF ATG $7^{-1-}$ were treated with MBR for $24 \mathrm{~h}$. Cell viability was analyzed by MTS assay. Error bars represent S.D. from triplicate experiments. ${ }^{\star *} P<0.01$ represents a statistically significant difference

thus execute their function during the treatment. Interestingly, as shown in Figure 7c, Beclin-1 and its mutant types all bound with caspase-8, whereas binding with caspase- 3 was hardly detected. Of note, the binding affinity of caspase-8 with Beclin1 S91/94A was weaker than that of Beclin-1 WT and Beclin-1 S91/94D, which needs further study. We also observed that the binding affinity of AMPK with Beclin-1 was increased after treatment of MBR in both Beclin-1 WT and its mutant types. These observations were confirmed by immunoprecipitating assay with endogenous Beclin-1 proteins (Figure 7d). Data from Figure 7d reveal that endogenous Beclin-1 indeed associated with AMPK and caspase-8 but not caspase-3. Notably, the binding affinity of Beclin-1 and AMPK was increased after MBR treatment.

D133 and D146 of Beclin-1 are known to be cleaved by caspase-8 during apoptosis. HCT116 Beclin-1 knock-in (Beclin-1 KI) cell line with double-mutant (DM; D133A/ D146A) was generated by homologous recombination. ${ }^{25}$ As shown in Figures $7 e$ and $\mathrm{f}, \mathrm{MBR}$-induced Beclin-1 cleavage was abolished in Beclin-1 $\mathrm{KI}$ cells, restoring Beclin-1's autophagy-promoting function as well as suppressing MBRinduced apoptosis.

Taken together, we summarized our observations in Figure 7g. MBR treatment causes mitochondrial dysfunction and AMPK activation. AMPK-mediated Beclin-1 phosphorylation is sufficient to induce Beclin-1 cleavage and thus contributes to the synergistic induction of apoptosis by decreasing autophagy; specifically, blocking Beclin-1 cleavage promotes autophagy and suppresses the apoptosis induced by MBR.

\section{Discussion}

Multidrug treatment can potentially overcome the resistance developed by single agents as well as reduce their side effects. $^{26,27}$ Here we have presented a novel combination treatment of melphalan in combination with the proteasome inhibitor bortezomib and the mTOR inhibitor rapamycin for colon cancer cells, as well as colon cancer stem cells, and demonstrated that this multidrug treatment-induced synergistic apoptosis mediated by AMPK activation through facilitation of Beclin-1 cleavage.

In recent research, the relationship between cancer cell growth and cell metabolism has been emphasized, highlighting the role of AMPK as one of the main players. ${ }^{28}$ AMPK is a eukaryotic heterotrimeric $(\alpha, \beta$ and $\gamma$ ) protein kinase activated in response to environmental stresses such as glucose deprivation and hypoxia, which produce changes in cellular ATP levels, resulting in phosphorylation of AMPK at Thr 172. Chemotherapy with certain drugs can activate AMPK to increase cell death and apoptosis. ${ }^{29,30}$ Rapamycin and UPS (ubiquitin-proteasome system) inhibitors may upregulate AMPK activity. ${ }^{31,32}$ It has been found that AMPK is involved in both cell survival and cell death pathways, 


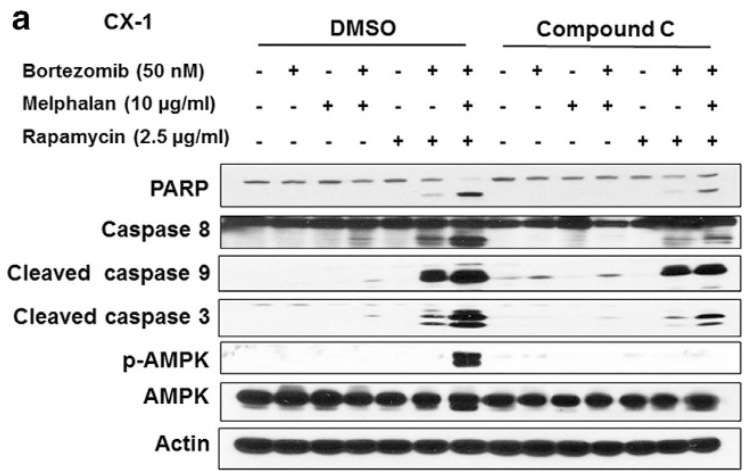

C

HCT116

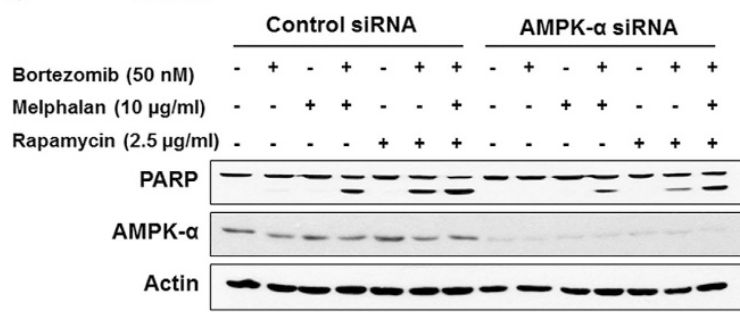

b

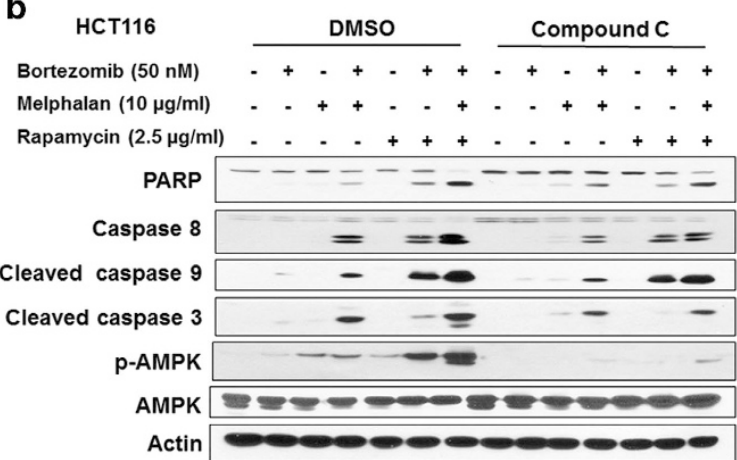

d $\mathrm{CX}-1$

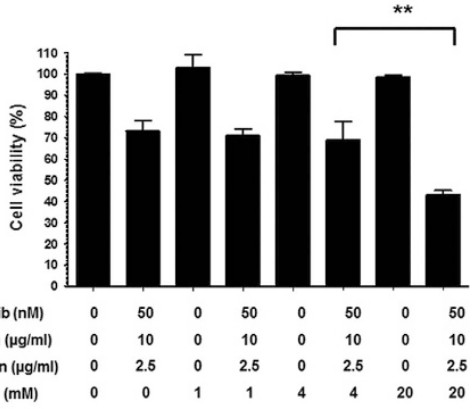

e HCT116

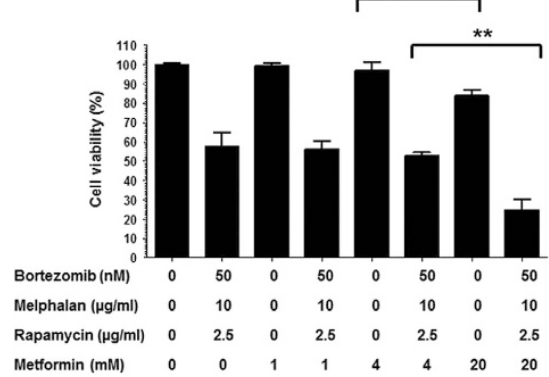

f $\mathrm{CX}-1$

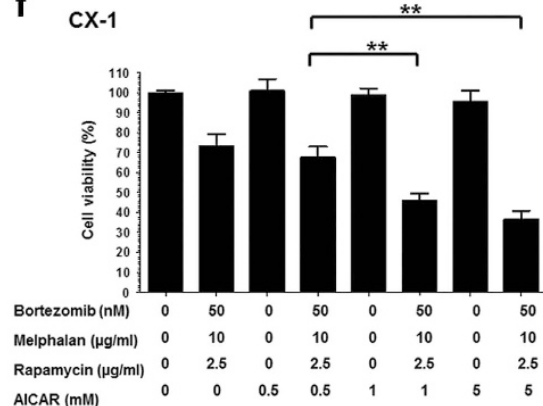

g

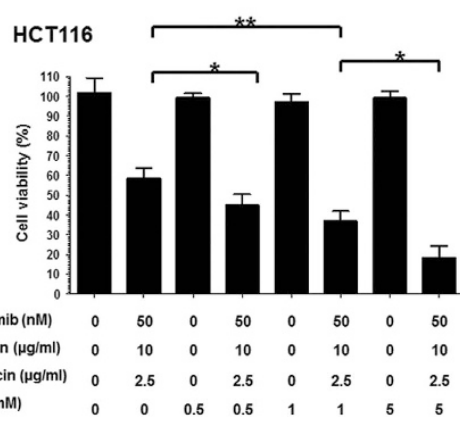

Figure 4 The role of AMPK in the MBR-induced apoptosis. (a and b) CX-1 (a) and HCT116 (b) cells were pretreated with $10 \mu$ M AMPK inhibitor compound C followed by treatment with MBR for $24 \mathrm{~h}$. After treatment, PARP, caspase-8, caspase-9, caspase-3, p-AMPK and AMPK were detected by immunoblotting. (c) HCT116 cells were transfected with nonsense sequence (control) or AMPK- $\alpha$ siRNA targeting AMPK- $\alpha$ mRNA. After $48 \mathrm{~h}$, cells were treated with MBR. The levels of AMPK- $\alpha$ and PARP were detected by immunoblotting. Actin was used as a loading control. ( $\mathbf{d}$ and $\mathbf{e})$ CX-1 (d) and HCT116 (e) cells were pretreated for 30 min with metformin (1-20 mM) followed by treatment with MBR for $24 \mathrm{~h}$. Cell viability was analyzed by MTS assay. Error bars represent S.D. from triplicate experiments. ${ }^{\star \star} P<0.01$ represents a statistically significant difference. (f and $\mathbf{g}$ ) CX-1 (f) and HCT116 (g) cells were pretreated for $30 \mathrm{~min}$ with AICAR $(0.5-5 \mathrm{mM})$ followed by treatment with MBR for $24 \mathrm{~h}$. Cell viability was analyzed by MTS assay. Error bars represent S.D. from triplicate experiments. ${ }^{*} P<0.05$ and ${ }^{* *} P<0.01$ represents a statistically significant difference

depending on the severity of energy stresses, drug action and cell types. Many researchers have reported that activation of AMPK induces apoptosis in cancer cells by inhibition of fatty acid synthase, phosphorylation of p53 or stimulation of the mitochondrial apoptotic pathway. ${ }^{33-38}$

In our current study, we observed significant AMPK activation in MBR treatment. AMPK inhibitor compound C and AMPK- $a$ siRNA suppressed MBR-induced apoptosis, indicating the proapoptotic effect of AMPK in the combinatorial treatment of MBR. This observation was also supported by experiments using AMPK activator metformin and AICAR. Interestingly, we observed that AMPK was activated at two stages. Early AMPK activation-induced autophagy, whereas late AMPK activation resulted in significant apoptosis. Autophagy, a catabolic degradation process, has recently emerged as an important stress response and cell death regulatory mechanism. The process of conventional macroautophagy is dependent on Atg7 (ubiquitin-activating enzyme (E1)-like) and Beclin-1. ${ }^{39}$ We observed that MBR treatmentinduced apoptosis was enhanced in MEF ATG7 ${ }^{-/-}$cells, indicating that blockage of autophagy promoted apoptosis in MBR treatment. We also observed that autophagy decreased in the combination of MBR compared with bortezomib alone. Thus, these results indicate the role of AMPK in cross-talk between apoptosis and autophagy in the multidrug treatment.

Beclin-1, a mammalian homolog of yeast Atg6, functions in autophagy by initiating autophagosome formation in combination with Vps34 (a class III PI-3 kinase that generates Ptdlns3P) and with Vps15 and Atg14; ${ }^{40}$ Beclin-1 then regulates autophagosome maturation by binding to UVRAG 
a

HCT116

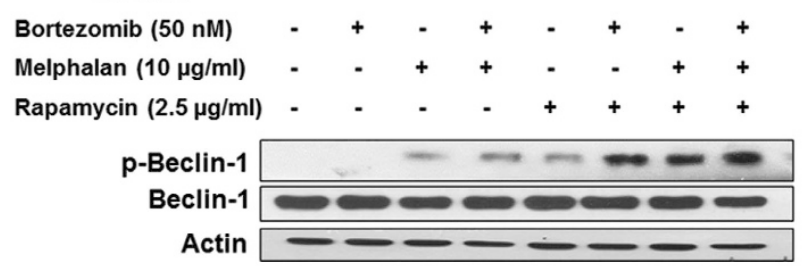

b CX-1

Bortezomib $(50 \mathrm{nM})++\quad+\quad+-++$

Melphalan $(10 \mu \mathrm{g} / \mathrm{ml})-e^{-}++\infty++$

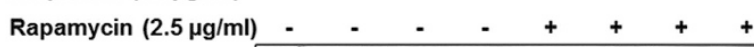

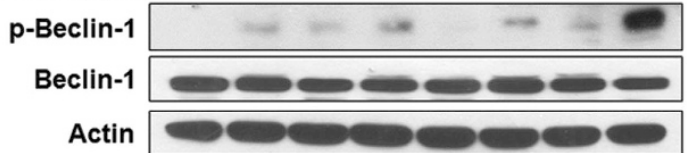

c

HCT116

Bortezomib (50 nM) Melphalan $(10 \mu \mathrm{g} / \mathrm{ml})$

Rapamycin $(2.5 \mu \mathrm{g} / \mathrm{ml})$

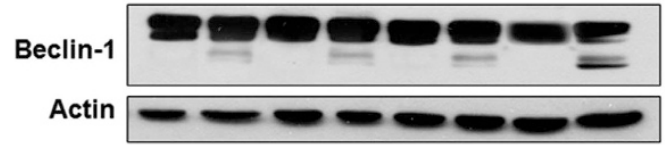

d

Tu-22

Bortezomib (10 $\mathrm{nM})-+++++$

Melphalan $(10 \mu \mathrm{g} / \mathrm{ml}) \quad-\quad-\quad+\quad+\quad-\quad+\quad+$

Rapamycin $(10 \mu \mathrm{g} / \mathrm{ml}) \quad-\quad-\quad-\quad+\quad+\quad+\quad+\quad+$

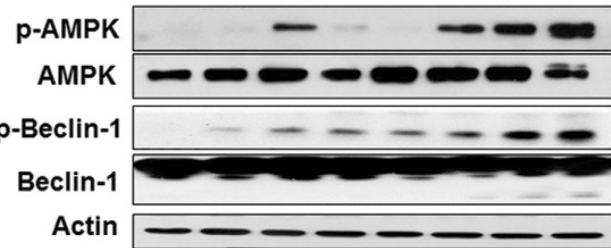

e

HCT116

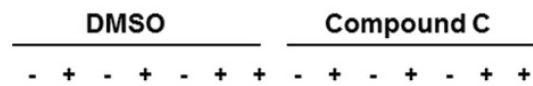

Bortezomib (50 nM) - + - + - + - + - + + +

Melphalan $(10 \mu \mathrm{g} / \mathrm{ml})-+_{+}+-++-++-+_{+}+$

Rapamycin $(2.5 \mu \mathrm{g} / \mathrm{ml}) \quad-\quad-e_{-}+++-c_{-}++++$

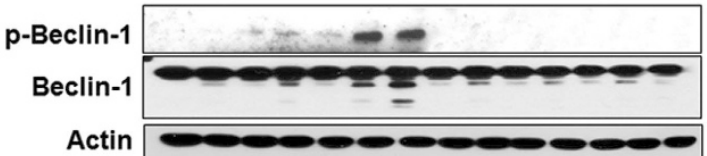

f $\quad C X-1$

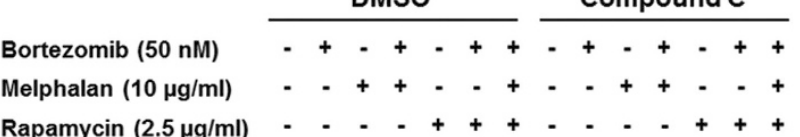

Rapamycin $(2.5 \mu \mathrm{g} / \mathrm{ml}) \quad-\quad-e^{-}++++_{+}++_{+}+$

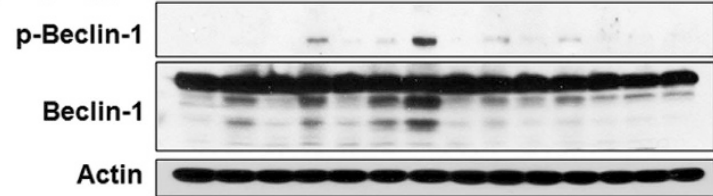

g

CX-1

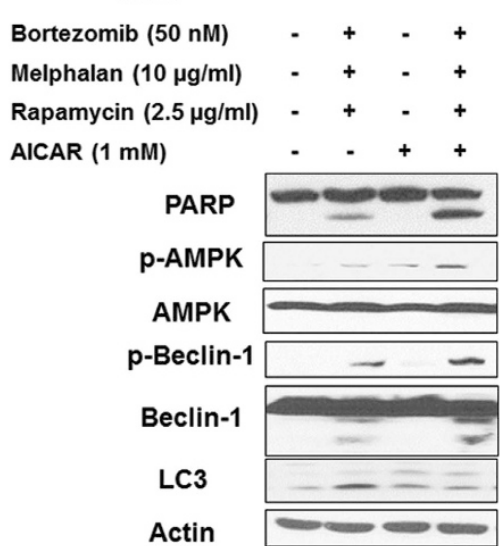

HCT116

Bortezomib (50 nM) - + - +

Melphalan $(10 \mu \mathrm{g} / \mathrm{ml})-++$

Rapamycin $(2.5 \mu \mathrm{g} / \mathrm{ml}) \quad-++\quad+$

AICAR (1 mM)

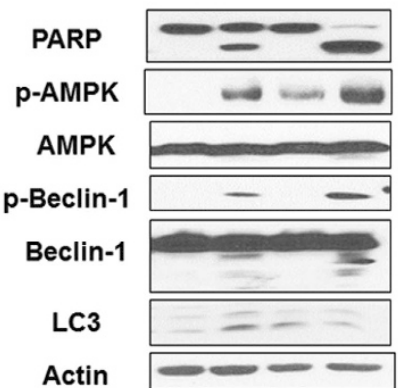

Figure 5 AMPK- $\alpha$ activation-induced Beclin-1 phosphorylation at Ser 93/96 and Beclin-1 cleavage. (a and b) HCT116 (a) and CX-1 (b) cells were treated with MBR for $24 \mathrm{~h}$ and p-Beclin-1 (Ser 93/96) and Beclin-1 were detected by immunoblotting in HCT116 and CX-1 cells. (c) After treatment, Beclin-1 cleavage was detected by immunoblotting in HCT116 cells. (d) Tu-22 cells were treated with MBR for $24 \mathrm{~h}$ and $\mathrm{p}-\mathrm{AMPK}, \mathrm{AMPK}, \mathrm{p}-\mathrm{Beclin}-1$ (Ser 93/96) and Beclin-1 were detected by immunoblotting. (e and f) HCT116 (e) and CX-1 (f) cells were pretreated with $10 \mu \mathrm{M}$ compound C followed by MBR for $24 \mathrm{~h}$, and Beclin-1 phosphorylation at Ser $93 / 96$ and Beclin-1 cleavage were detected by immunoblotting. (g) CX-1 and HCT116 cells were pretreated for 30 min with $1 \mathrm{mM}$ AICAR followed by treatment with MBR for $24 \mathrm{~h}$. After treatment, PARP, p-AMPK, AMPK, p-Beclin-1 (Ser 93/96), Beclin-1 and LC3 were detected by immunoblotting. Actin was used to confirm the equal amount of proteins loaded in each lane 
a

CX-1

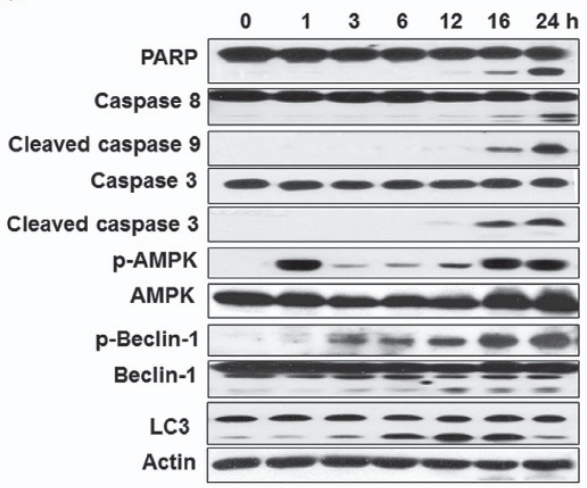

b HCT116

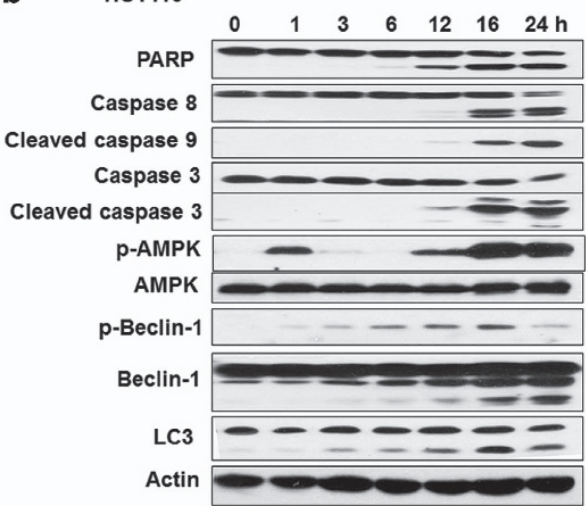

C

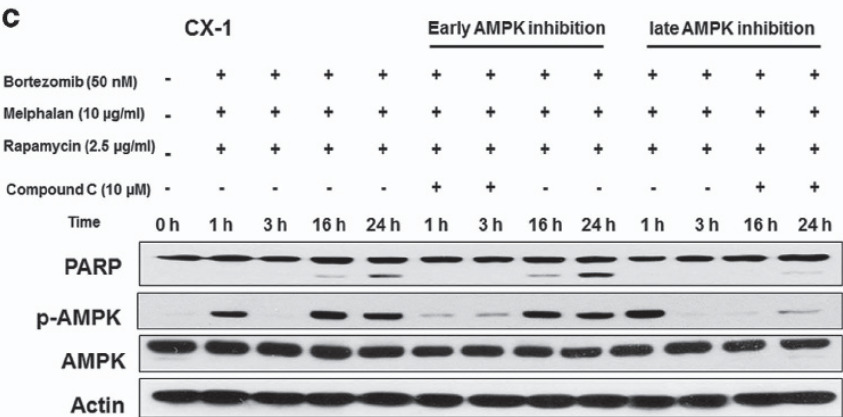

d

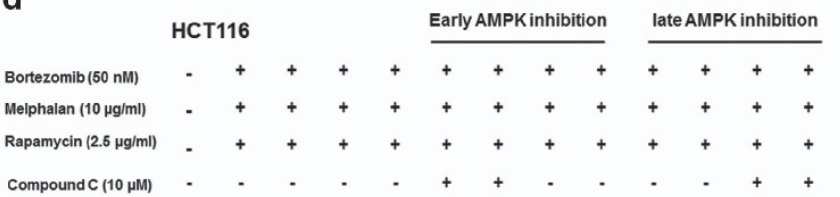

Time

$0 \mathrm{~h} \quad 1 \mathrm{~h} \quad 3 \mathrm{~h} \quad 16 \mathrm{~h} \quad 24 \mathrm{~h} \quad 1 \mathrm{~h} \quad 3 \mathrm{~h} \quad 16 \mathrm{~h} \quad 24 \mathrm{~h} \quad 1 \mathrm{~h} \quad 3 \mathrm{~h} \quad 16 \mathrm{~h} \quad 24 \mathrm{~h}$

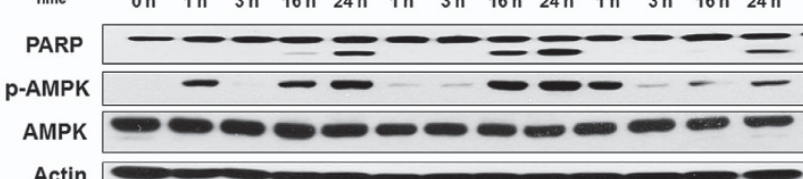

Actin

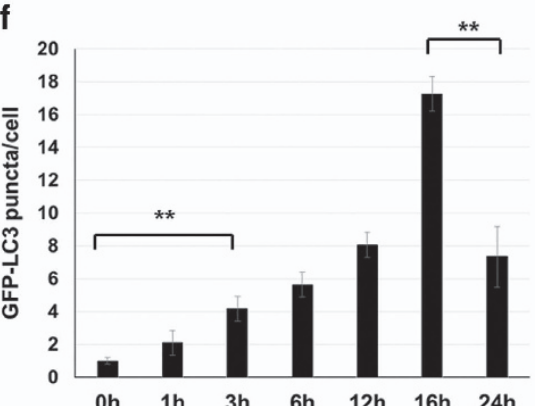

g

HCT116

DAPI LC3-GFP Merge

oh

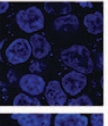

$x^{2} x^{2}$

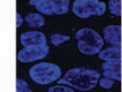

$-43$

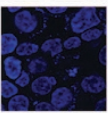

$3^{5}$

28
3
2

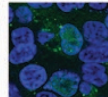

$3 \mathrm{~h}$

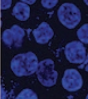

$\cos 6$

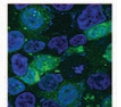

$12 \mathrm{~h}$

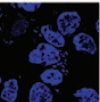

3.

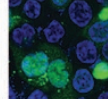

$16 \mathrm{~h}$
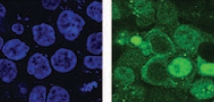

$24 \mathrm{~h}$
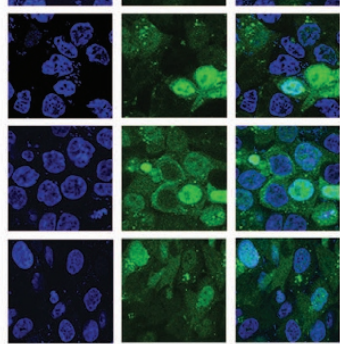

Oh $\quad 1 \mathrm{~h} \quad 3 \mathrm{~h} \quad 6 \mathrm{~h} \quad 12 \mathrm{~h} \quad 16 \mathrm{~h} \quad 24 \mathrm{~h}$

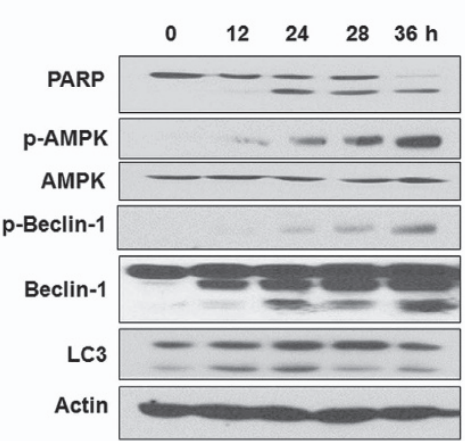

Figure 6 The kinetics of AMPK- $\alpha$ activation and Beclin-1 phosphorylation and cleavage during treatment with MBR. CX-1 (a) and HCT116 (b) cells were treated with MBR for various times (1-24 h). After treatment, cell lysates were immunoblotted with anti-PARP, anti-caspase-8, anti-caspase-9, anti-caspase-3, anti-phospho-AMPK- $\alpha$, anti-AMPK- $\alpha$, anti-phospho-Beclin-1, anti-Beclin-1 or anti-LC3 antibody. Actin was used to confirm the equal amount of proteins loaded in each lane. (c and d) CX-1 (c) and HCT116 (d) cells were treated with MBR in the presence of $10 \mu \mathrm{M}$ compound $\mathrm{C}$ from 0 to $4 \mathrm{~h}$ (at early time point and washed with phosphate-buffered saline at $4 \mathrm{~h}$ ) or from 10 to $24 \mathrm{~h}$ (at late time point). After treatment, PARP, p-AMPK, AMPK and actin were detected by immunoblotting. (e) After treatment, LC3 punta formation was analyzed with confocal microscope in HCT116 cells. (f) Quantification of GFP-LC3 puncta formations. ${ }^{* \star} P<0.01$ represents a statistically significant difference. (g) HCT116 cells were treated with MBR for various times (12-36 h). After treatment, cell lysates were immunoblotted with anti-PARP, anti-phospho-AMPK- $\alpha$, anti-AMPK- $\alpha$, anti-phospho-Beclin-1, anti-Beclin-1 or anti-LC3 antibody. Actin was used to confirm the equal amount of proteins loaded in each lane 
and Rubicon. ${ }^{41}$ Cross-talk between apoptosis and autophagy was associated with caspase-mediated cleavage of Beclin-1, which both destroys its proautophagic activity ${ }^{22,25,42,43}$ and can then amplify mitrochondrion-mediated apoptosis through the cleaved C-terminal fragment. ${ }^{24}$ However, how Beclin-1 cleavage is regulated is largely unknown.

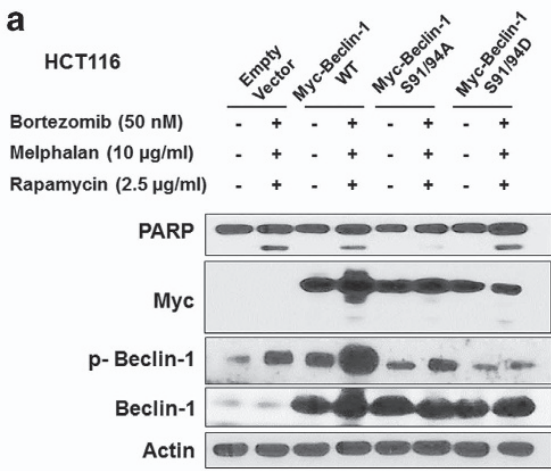

C

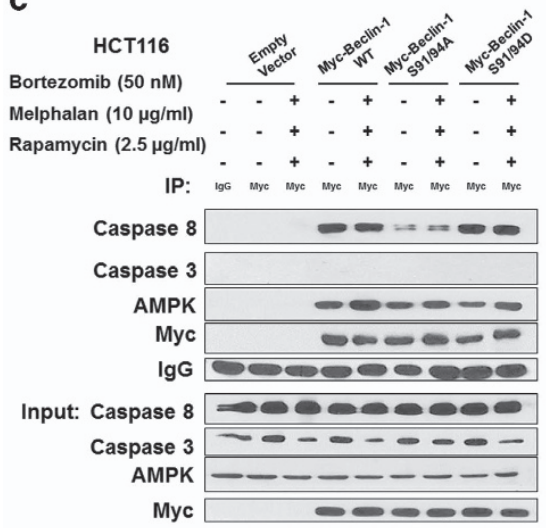

f

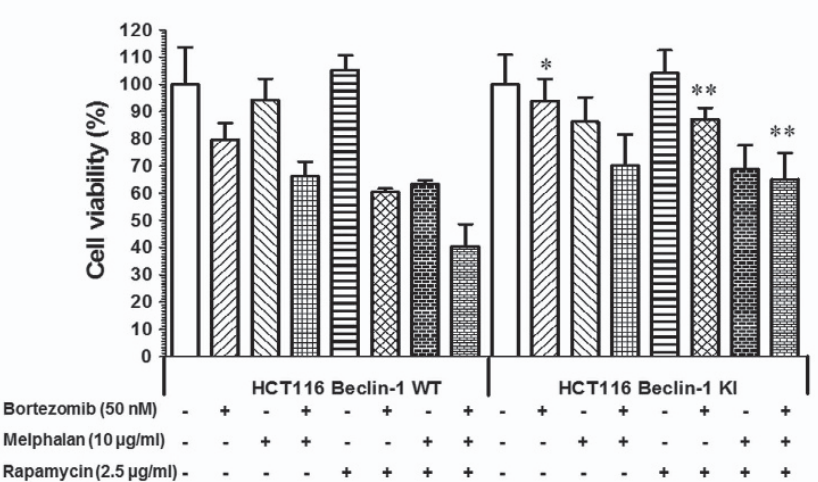

b

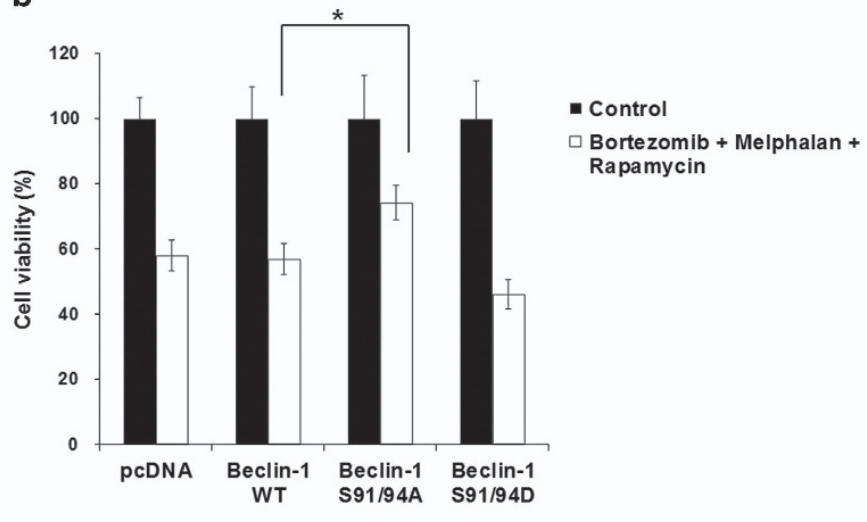

e

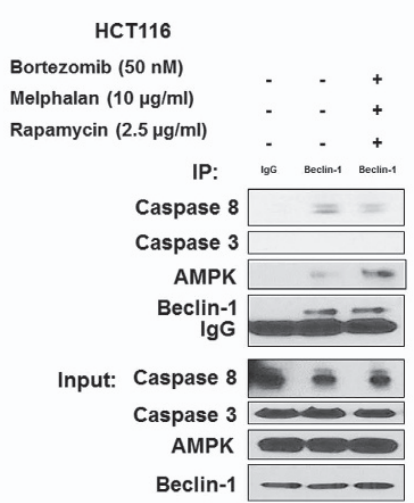

g

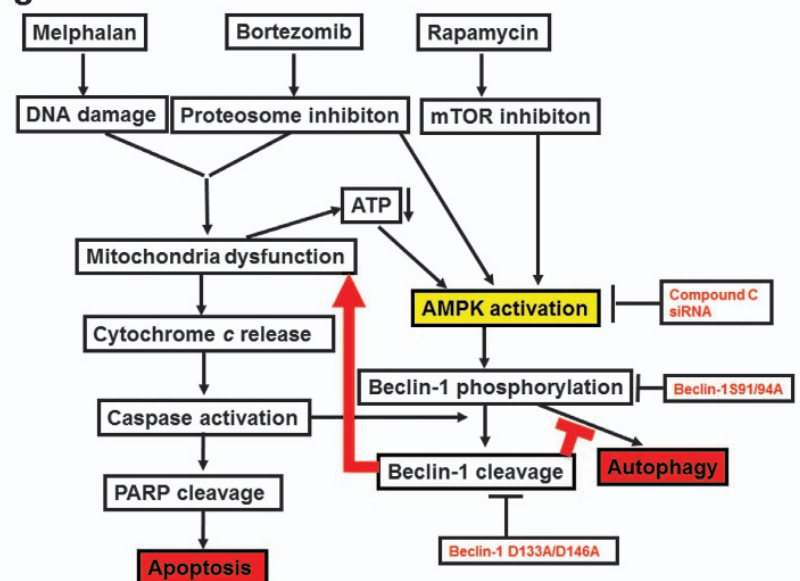

Figure 7 Beclin-1 phosphorylation at Ser 91/94 was a prerequisite for Beclin-1 cleavage and the cleavage of Beclin-1 contributed to the synergistic induction of apoptosis. HCT116 cells were transiently transfected with empty vector (pcDNA), Myc-Beclin-1 WT, Myc-Beclin-1 S91/94A and Myc-Beclin-1 S91/94D; 48 h later cells were treated with MBR for $24 \mathrm{~h}$. (a) PARP, Myc, phosphorylated Beclin-1 and Beclin-1 were detected by immunoblotting. Actin was shown as an internal standard. (b) Cell viability was determined by MTS assay. ${ }^{*} P<0.05$ represents a statistically significant difference. (c) Cell lysates were immunoprecipitated with anti-Myc antibody or lgG and then immunoblotted with anticaspase-8/3, anti-AMPK- $\alpha$ or anti-Myc antibody (upper panels). The presence of caspase-8/3, AMPK- $\alpha$ and Myc in the lysates was examined (lower panels). (d) HCT116 cells were treated with MBR for $24 \mathrm{~h}$ and cell lysates were immunoprecipitated with anti-Beclin-1 antibody or lgG and then immunoblotted with anti-caspase-8/3, anti-AMPK- $\alpha$ or antiBeclin-1 antibody (upper panels). The presence of caspase-8/3, AMPK- $\alpha$ and Beclin-1 in the lysates was examined (lower panels). (e) Parental HCT116 (HCT116 Beclin-1 WT) and HCT116 Beclin-1 KI (DM; D133A/D146A) cells were treated with MBR and immunoblotted with anti-PARP, anti-Beclin-1 or anti-LC3 antibody. Actin was used to confirm the equal amount of proteins. (f) After treatment, cell viability was determined by MTS assay. ${ }^{*} P<0.05$ and ${ }^{\star *} P<0.01$ represent a statistically significant difference. (g) A schematic diagram of the role of AMPK in cross-talk between apoptosis and autophagy 
Beclin-1 phosphorylation sites reported include: Thr $119,{ }^{44}$ Ser $14,{ }^{45}$ Ser $93 / 96^{23}$ and Ser $234 / 295 .{ }^{46}$ Recently, AMPK was reported to phosphorylate directly Beclin-1 at Ser 93/96 for activating proautophagy Vps34 complex and subsequently inducing autophagy. ${ }^{23}$ The question remains as to how AMPKmediated phosphorylation of Beclin-1 at Ser 93/96 regulates caspase-8-associated cleavage of Beclin-1. Here, we reported that Beclin-1 phosphorylation at Ser 93/96 is a prerequisite for Beclin-1 cleavage and thus contributes to the synergistic induction of apoptosis. AMPK inhibitor compound C inhibited both Beclin-1 phosphorylation at Ser 93/96 and Beclin-1 cleavage. In addition, Myc-tagged murine Beclin-1 S91/94A mutant was resistant to cleavage and suppressed MBR-induced apoptosis. Moreover, the binding affinity of Beclin-1 S91/94A with caspase-8 was decreased, providing one possible mechanism of AMPK-mediated Beclin-1 cleavage through its phosphorylation and formation of an AMPKBeclin-1-caspase-8 complex. Beclin-1 DM (D133A/D146A) knock-in HCT116 cells partially abolished the apoptosis, confirming the role of Beclin-1 cleavage in the multidrug treatment.

Taken together, we present here that a novel multidrug treatment of chemotherapeutic agent in combination with proteasome inhibitor and mTOR inhibitor induced robust apoptosis in colon cancer cells as well as colon cancer stem cells, an apoptotic process that is linked with altered cellular metabolism and AMPK activation. We believe that these results demonstrate for the first time that the induction of apoptosis by AMPK is associated with Beclin-1 cleavage through Beclin-1 phosphorylation at Ser 93/96. Melphalan, bortezomib and rapamycin are all commonly used FDAapproved drugs and could be considered for colorectal hepatic metastases treatment in clinics.

\section{Materials and Methods}

Cell cultures and transfection. Human colorectal carcinoma CX-1 cells, which were obtained from Dr. JM Jessup (National Institutes of Health, Bethesda, MD, USA), ${ }^{47}$ were cultured in RPMI-1640 medium (Gibco-BRL, Grand Island, NY, USA) containing $10 \%$ fetal bovine serum (HyClone, Logan, UT, USA). The human colorectal carcinoma HCT116 Bax-containing $\left(\mathrm{Bax}^{+/+}\right)$and Bax-deficient $\left(\mathrm{Bax}^{-1-}\right)$ cell lines were kindly provided by Dr. B Vogelstein (Johns Hopkins University, Baltimore, MD, USA); these cell lines were cultured in McCoy's 5A medium (GibcoBRL) containing $10 \%$ fetal bovine serum. ${ }^{48}$ Human colon cancer stem Tu-22 cells were established by Dr. E Lagasse (University of Pittsburgh, Pittsburgh, PA, USA) and cultured in DMEM/F12 medium (Gibco-BRL) containing $0.5 \%$ fetal bovine serum (HyClone) and 1\% insulin, transferrin and selenium (Fisher Scientific, Pittsburgh, PA, USA). ${ }^{49}$ MEF ATG7 ${ }^{+/+}$and MEF ATG7 ${ }^{-1-}$ cell lines, a kind gift from Dr. Masaaki Komatsu (The Tokyo Metropolitan Institute of Medical Science, Tokyo, Japan), were cultured in DMEM medium (Gibco-BRL) containing 10\% fetal bovine serum. All the cells were kept in a $37^{\circ} \mathrm{C}$ humidified incubator with $5 \% \mathrm{CO}_{2}$. For transient transfection, cells were transfected with Lipofectamine 2000 (Life Technologies, Carlsbad, CA, USA) and were treated $48 \mathrm{~h}$ after transfection.

Reagents and antibodies. Bortezomib and melphalan were from Millennium Pharmaceuticals (Cambridge, MA, USA) and GlaxoSmithKline (Coraopolis, PA, USA), respectively. Rapamycin, metformin, aminoimidazole carboxamide ribonucleotide and protease inhibitor cocktail were obtained from Sigma-Aldrich (St. Louis, MO, USA). AMPK inhibitor (compound C) was from Calbiochem (Darmstadt, Germany). Myc-Beclin-1 WT, Myc-Beclin-1 S91/94A and Myc-Beclin-1 S91/94D were kindly provided by Dr. Kun-Liang Guan (University of California at San Diego, La Jolla, CA, USA). Anti-Myc, anti-Bax, anti-caspase-8, anti-caspase-9, anticaspase-3, anti-phosphorylated AMPK- $\alpha /$ AMPK- $\alpha$, anti-phosphorylated Beclin-1 (Ser 93/96), anti-COX-IV and anti-PARP antibody were from Cell Signaling
(Danvers, MA, USA). Anti-LC3 and anti-actin antibody were from Sigma-Aldrich. Anti-Beclin-1 and anti-cytochrome $c$ antibody were from BD PharMingen (San Jose, CA, USA).

MTS assays. MTS studies were carried out using the Promega CellTiter 96 AQueous One Solution Cell Proliferation Assay (Promega, Madison, WI, USA). CX-1 cells $\left(1 \times 10^{5}\right)$ were grown in RPMI-1640 medium containing $10 \%$ fetal bovine serum in tissue culture-coated 96-well plates and treated with drugs for $24 \mathrm{~h}$. Cells were then treated with $20 \mu \mathrm{l}$ MTS/phenazine methosulfate solution for $1-4 \mathrm{~h}$ at $37^{\circ} \mathrm{C}$. Absorbance at $490 \mathrm{~nm}$ was determined using an enzyme-linked immunosorbent assay plate reader.

$\mathrm{Cl}$ analysis. Cls were calculated using CompuSyn software program (ComboSyn Inc., Paramus, NJ, USA). Base on $\mathrm{Cl}$ values, extent of synergism/ antagonism is determined. In general, $\mathrm{Cl}$ value below 1 suggests synergy, whereas $\mathrm{Cl}$ value above 1 indicates antagonism between the drugs. $\mathrm{Cl}$ values in the range of 0.9-1.10 would mainly indicate additive effects, those between 0.9 and 0.85 would suggest slight synergy, those in the range of $0.7-0.3$ are indicative of moderate synergy and those $<0.3$ would suggest strong synergy.

Annexin $\mathbf{V}$ binding. Cells were treated with drugs, harvested by trypsinization, washed with serum-free medium and suspended in binding buffer (Annexin V-fluorescein isothiocyanate (FITC) Staining Kit; BD PharMingen). This cell suspension was stained with mouse anti-human Annexin $\mathrm{V}$ antibody and propidium iodide (PI) and immediately analyzed by flow cytometry.

Immunoprecipitation. Briefly, cells were lysed in CHAPS lysis buffer with protease inhibitor cocktail (Calbiochem). The lysate $(0.5-1 \mathrm{mg})$ was incubated with $1.5 \mu \mathrm{g}$ of anti-Myc/Beclin-1 antibody or rabbit/mouse IgG (Santa Cruz, Dallas, TX, USA) at $4{ }^{\circ} \mathrm{C}$ overnight, followed by the addition of protein G PLUS-agarose beads (Santa Cruz) and rotation at room temperature for $2 \mathrm{~h}$ followed by immunoblot analysis.

Immunoblot analysis. Cells were lysed with Laemmli lysis buffer and boiled for $10 \mathrm{~min}$. The protein content was measured with BCA Protein Assay Reagent (Pierce, Rockford, IL, USA), separated by sodium dodecyl sulfate-polyacrylamide gel electrophoresis (SDS-PAGE) and electrophoretically transferred to nitrocellulose membrane. The nitrocellulose membrane was blocked with $5 \%$ nonfat dry milk in PBS-Tween-20 $(0.1 \%, v / v)$ for $1 \mathrm{~h}$ and incubated with primary antibody at room temperature for $2 \mathrm{~h}$. Horseradish peroxidase-conjugated anti-rabbit or anti-mouse IgG was used as the secondary antibody. Immunoreactive protein was visualized by the chemiluminescence protocol.

JC-1 mitochondrial membrane potential assay. After drug treatment, cells were stained with JC-1 Mitochondrial Membrane Potential Detection Kit (Invitrogen, Carlsbad, CA, USA) for $10 \mathrm{~min}$ and analyzed by flow cytometry. Fluorescence intensity was measured with the FACScan flow cytometer (Beckman Coulter, Hialeah, FL, USA). Results were analyzed with CellQuest software (Becton Dickinson Immunocytometry Systems, San Jose, CA, USA).

ATP assay. The ATP content in whole-cell extracts was determined with a luminescent ATP Detection Kit (ATPlite, Perkin-Elmer, Akron, OH, USA) according to the manufacturer's instructions. The luminescence intensity was measured by using a microplate reader (Synergy 2; BioTek Instruments, Winooski, VT, USA). In parallel, the cell numbers in whole-cell samples were counted by Trypan blue exclusion assay. The results were expressed as relative ATP level compared with controls after normalizing for cell numbers.

Measurement of cytochrome $c$ release. To determine the release of cytochrome $c$ from the mitochondria, cells growing in $100 \mathrm{~mm}$ dishes were used. After drug treatment, mitochondrial and cytosolic fractions were prepared using Mitochondrial Fractionation Kit (Active Motif, Carlsbad, CA, USA) following company instructions with reagents included in the kit. Cytosolic fractions were subjected to SDS-PAGE gel electrophoresis and analyzed by immunoblotting using anticytochrome $c$ antibody.

Knockdown of AMPK- $a$ with siRNA oligomers. To generate AMPK- $\alpha$ knockdown cells, cells were transfected with $10 \mathrm{nM}$ of siRNA AMPK- $\alpha 1$ and 
AMPK- $\alpha 2$ and control siRNA from Sigma-Aldrich, using Lipofectamine 2000. Target sequences for preparing siRNAs of human AMPK- $\alpha 1$ and $\alpha 2$ were as follows: 5'-AGUGAAGGUUGGCAAACAUTT-3' (sense strand) and 5'-AUGUUUGCCA ACCUUCACUTT-3' (complement strand) for human AMPK- $\alpha$; ; $5^{\prime}$-GGAAGGUAG UGAAUGCAUATT-3' (sense strand) and 5'- UAUGCAUUCACUACCUUCCTT-3' (complement strand) for human AMPK- $\alpha 2 .^{50}$ Expression levels were determined by immunoblot analysis.

Analysis of GFP-LC3 puncta formation. Stably transduced HCT116 tumor cells expressing the GFP-LC3 gene were generated by lentiviral transfection of the PCT-autophagosome-GFP Vector (Lentiviral Laboratory of the Vector Core Facility of the University of Pittsburgh) and selected with puromycin. HCT116 cells were treated with $10 \mu \mathrm{g} / \mathrm{ml}$ melphalan, along with $50 \mathrm{nM}$ bortezomib and/or $2.5 \mu \mathrm{g} / \mathrm{ml}$ rapamycin for $24 \mathrm{~h}$. Cells were washed three times with PBS, followed by fixation in $4 \%$ paraformaldehyde for $15 \mathrm{~min}$. Nuclei were stained with DAPI (Cell Signaling). Slides were mounted and visualized in $0.4 \mu \mathrm{m}$ sections using an OlympusFluoview 1000 confocal microscope and the companion software FV10ASW2.1 (Olympus, Center Valley, PA, USA) under a $\times 63$ oil immersion objective. GFP-LC3 puncta formation was quantified by counting at least 300 cells for each sample and plotted as mean \pm S.D. of three independent experiments.

Statistical analysis. Statistical analysis was carried out using Graphpad InStat 3 software (GraphPad Software, San Diego, CA, USA). Data showing comparisons between two groups were assessed using the Student's $t$-test. Comparisons among more than two groups were carried out using ANOVA with the appropriate post hoc testing. Statistical significance is marked with asterisks $\left({ }^{*} P<0.05\right.$ and $\left.{ }^{*} P<0.01\right)$.

\section{Conflict of Interest}

The authors declare no conflict of interest.

Acknowledgements. This work was supported by the following grants: $\mathrm{NCl}$ R01CA140554 (YJL), R01CA106348 (LZ), R01CA172136 (LZ) and R01CA160417 (DT); National Research Foundation of Korea Program NRF-2013R1A2A2A01014170 (YTK); and Nobel Laureates Invitation Program of Seoul National University (YTK). This project used the UPCI Core Facility and was supported in part by award P30CA047904.

\section{Author contributions}

Conceived and designed the experiments: XS, YJL; performed the experiments: XS, SYK; analyzed the data: XS, YJL; contributed reagents/materials/analysis tools: LZ, DT, DLB, YTK; wrote the paper: XS, YJL.

1. Ruers T, Bleichrodt RP. Treatment of liver metastases, an update on the possibilities and results. Eur J Cancer 2002; 38: 1023-1033.

2. Jemal A, Bray F, Center MM, Ferlay J, Ward E, Forman D. Global cancer statistics. $C A$ Cancer J Clin 2011; 61: 69-90.

3. Poultsides GA, Paty PB. Reassessing the need for primary tumor surgery in unresectable metastatic colorectal cancer: overview and perspective. Ther Adv Med Oncol 2011; 3: 35-42.

4. Cirocchi R, Trastulli S, Boselli C, Montedori A, Cavaliere D, Parisi A et al. Radiofrequency ablation in the treatment of liver metastases from colorectal cancer. Cochrane Database Syst Rev 2012; 6: CD006317.

5. Vogl TJ, Farshid P, Naguib NN, Darvishi A, Bazrafshan B, Mbalisike E et al. Thermal ablation of liver metastases from colorectal cancer: radiofrequency, microwave and laser ablation therapies. Radiol Med 2014; 119: 451-461.

6. Townsend A, Price T, Karapetis C. Selective internal radiation therapy for liver metastases from colorectal cancer. Cochrane Database Syst Rev 2009; 7: CD007045.

7. Reddy SK, Kesmodel SB, Alexander HR Jr.. Isolated hepatic perfusion for patients with liver metastases. Ther Adv Med Oncol 2014; 6: 180-194.

8. Song X, Kim SY, Lee YJ. Evidence for two modes of synergistic induction of apoptosis by mapatumumab and oxaliplatin in combination with hyperthermia in human colon cancer cells. PLoS One 2013; 8: e73654.

9. Song X, Kim SY, Lee YJ. The role of Bcl-xL in synergistic induction of apoptosis by mapatumumab and oxaliplatin in combination with hyperthermia on human colon cancer. Mol Cancer Res 2012; 10: 1567-1579.

10. Song X, Kim HC, Kim SY, Basse P, Park BH, Lee BC et al. Hyperthermia-enhanced TRAILand mapatumumab-induced apoptotic death is mediated through mitochondria in human colon cancer cells. J Cell Biochem 2012; 113: 1547-1558.
11. Wang C, Youle RJ. The role of mitochondria in apoptosis*. Annu Rev Genet 2009; 43 95-118.

12. Lucken-Ardjomande S, Martinou JC. Newcomers in the process of mitochondrial permeabilization. J Cell Sci 2005; 118 (Part 3): 473-483.

13. Souliotis VL, Dimopoulos MA, Sfikakis PP. Gene-specific formation and repair of DNA monoadducts and interstrand cross-links after therapeutic exposure to nitrogen mustards. Clin Cancer Res 2003; 9: 4465-4474.

14. Fu D, Calvo JA, Samson LD. Balancing repair and tolerance of DNA damage caused by alkylating agents. Nat Rev Cancer 2012; 12: 104-120.

15. Garrido C, Brunet M, Didelot C, Zermati Y, Schmitt E, Kroemer G. Heat shock proteins 27 and 70: anti-apoptotic proteins with tumorigenic properties. Cell Cycle 2006; 5: 2592-2601.

16. Fennell DA, Chacko A, Mutti L. BCL-2 family regulation by the $20 \mathrm{~S}$ proteasome inhibitor bortezomib. Oncogene 2008; 27: 1189-1197.

17. Zhu K, Dunner K Jr., McConkey DJ. Proteasome inhibitors activate autophagy as a cytoprotective response in human prostate cancer cells. Oncogene 2010; 29: 451-462.

18. Guertin DA, Sabatini DM. An expanding role for mTOR in cancer. Trends Mol Med 2005; 11 353-361.

19. Faivre S, Kroemer G, Raymond E. Current development of mTOR inhibitors as anticancer agents. Nat Rev Drug Discov 2006; 5: 671-688.

20. Fasolo A, Sessa C. mTOR inhibitors in the treatment of cancer. Expert Opin Invest Drugs 2008; 17: 1717-1734.

21. Hanahan D, Weinberg RA. Hallmarks of cancer: the next generation. Cell 2011; 144: 646-674.

22. Kang R, Zeh HJ, Lotze MT, Tang D. The Beclin 1 network regulates autophagy and apoptosis. Cell Death Differ 2011; 18: 571-580.

23. Kim J, Kim YC, Fang C, Russell RC, Kim JH, Fan W et al. Differential regulation of distinct Vps34 complexes by AMPK in nutrient stress and autophagy. Cell 2013; 152: 290-303.

24. Wirawan E, Vande Walle L, Kersse K, Cornelis S, Claerhout S, Vanoverberghe I et al. Caspase-mediated cleavage of Beclin-1 inactivates Beclin-1-induced autophagy and enhances apoptosis by promoting the release of proapoptotic factors from mitochondria. Cell Death Dis 2010; 1: e18.

25. Li H, Wang P, Sun Q, Ding WX, Yin XM, Sobol RW et al. Following cytochrome c release, autophagy is inhibited during chemotherapy-induced apoptosis by caspase 8-mediated cleavage of Beclin 1. Cancer Res 2011; 71: 3625-3634.

26. Gottesman MM. Mechanisms of cancer drug resistance. Annu Rev Med 2002; 53: 615-627.

27. Zhou Z, Jing C, Zhang L, Takeo F, Kim H, Huang Y et al. Regulation of Rad17 protein turnover unveils an impact of Rad17-APC cascade in breast carcinogenesis and treatment. J Biol Chem 2013; 288: 18134-18145.

28. Green AS, Chapuis N, Lacombe C, Mayeux P, Bouscary D, Tamburini J. LKB1/AMPK/mTOR signaling pathway in hematological malignancies: from metabolism to cancer cell biology. Cell Cycle 2011; 10: 2115-2120.

29. Rocha GZ, Dias MM, Ropelle ER, Osorio-Costa F, Rossato FA, Vercesi AE et al. Metformin amplifies chemotherapy-induced AMPK activation and antitumoral growth. Clin Cancer Res 2011; 17: 3993-4005.

30. Hwang JT, Ha J, Park OJ. Combination of 5-fluorouracil and genistein induces apoptosis synergistically in chemo-resistant cancer cells through the modulation of AMPK and COX-2 signaling pathways. Biochem Biophys Res Commun 2005; 332: 433-440.

31. Habib SL, Kasinath BS, Arya RR, Vexler S, Velagapudi C. Novel mechanism of reducing tumourigenesis: upregulation of the DNA repair enzyme OGG1 by rapamycin-mediated AMPK activation and mTOR inhibition. Eur J Cancer 2010; 46: 2806-2820.

32. Padrissa-Altes S, Zaouali MA, Bartrons R, Rosello-Catafau J. Ubiquitin-proteasome system inhibitors and AMPK regulation in hepatic cold ischaemia and reperfusion injury: possible mechanisms. Clin Sci (Lond) 2012; 123: 93-98.

33. Baumann P, Mandl-Weber S, Emmerich B, Straka C, Schmidmaier R. Inhibition of adenosine monophosphate-activated protein kinase induces apoptosis in multiple myeloma cells. Anticancer Drugs 2007; 18: 405-410.

34. Shaw RJ, Kosmatka M, Bardeesy N, Hurley RL, Witters LA, DePinho RA et al. The tumor suppressor LKB1 kinase directly activates AMP-activated kinase and regulates apoptosis in response to energy stress. Proc Natl Acad Sci U S A 2004; 101: 3329-3335.

35. Saitoh M, Nagai K, Nakagawa K, Yamamura T, Yamamoto S, Nishizaki T. Adenosine induces apoptosis in the human gastric cancer cells via an intrinsic pathway relevant to activation of AMP-activated protein kinase. Biochem Pharmacol 2004; 67: 2005-2011.

36. Xiang X, Saha AK, Wen R, Ruderman NB, Luo Z. AMP-activated protein kinase activators can inhibit the growth of prostate cancer cells by multiple mechanisms. Biochem Biophys Res Commun 2004; 321: 161-167.

37. Kefas BA, Heimberg H, Vaulont S, Meisse D, Hue L, Pipeleers D et al. AICA-riboside induces apoptosis of pancreatic beta cells through stimulation of AMP-activated protein kinase. Diabetologia 2003; 46: 250-254.

38. Kefas BA, Cai Y, Ling Z, Heimberg H, Hue L, Pipeleers D et al. AMP-activated protein kinase can induce apoptosis of insulin-producing MIN6 cells through stimulation of c-Jun-Nterminal kinase. J Mol Endocrinol 2003; 30: 151-161.

39. Juenemann K, Reits EA. Alternative macroautophagic pathways. Int J Cell Biol 2012; 2012 189794.

40. Itakura E, Kishi C, Inoue K, Mizushima N. Beclin 1 forms two distinct phosphatidylinositol 3-kinase complexes with mammalian Atg14 and UVRAG. Mol Biol Cell 2008; 19: $5360-5372$. 
41. Matsunaga K, Saitoh T, Tabata K, Omori H, Satoh T, Kurotori N et al. Two Beclin 1-binding proteins, Atg14L and Rubicon, reciprocally regulate autophagy at different stages. Nat Cell Biol 2009; 11: 385-396.

42. Cho DH, Jo YK, Hwang JJ, Lee YM, Roh SA, Kim JC. Caspase-mediated cleavage of ATG6/Beclin-1 links apoptosis to autophagy in HeLa cells. Cancer Lett 2009; 274: 95-100.

43. Zhu Y, Zhao L, Liu L, Gao P, Tian W, Wang $X$ et al. Beclin 1 cleavage by caspase-3 inactivates autophagy and promotes apoptosis. Protein Cell 2010; 1: 468-477.

44. Zalckvar E, Berissi H, Mizrachy L, Idelchuk Y, Koren I, Eisenstein M et al. DAP-kinasemediated phosphorylation on the $\mathrm{BH} 3$ domain of beclin 1 promotes dissociation of beclin 1 from Bcl-XL and induction of autophagy. EMBO Rep 2009; 10: 285-292.

45. Russell RC, Tian Y, Yuan H, Park HW, Chang YY, Kim J et al. ULK1 induces autophagy by phosphorylating Beclin-1 and activating VPS34 lipid kinase. Nat Cell Biol 2013; 15 : 741-750.

46. Wang RC, Wei Y, An Z, Zou Z, Xiao G, Bhagat G et al. Akt-mediated regulation of autophagy and tumorigenesis through Beclin 1 phosphorylation. Science 2012; 338: 956-959.

47. Lee YJ, Galoforo SS, Battle P, Lee H, Corry PM, Jessup JM. Replicating adenoviral vectormediated transfer of a heat-inducible double suicide gene for gene therapy. Cancer Gene Ther 2001; 8: 397-404.

48. Cummins JM, Kohli M, Rago C, Kinzler KW, Vogelstein B, Bunz F. X-linked inhibitor of apoptosis protein (XIAP) is a nonredundant modulator of tumor necrosis factor-related apoptosis-inducing ligand (TRAIL)-mediated apoptosis in human cancer cells. Cancer Res 2004; 64: 3006-3008

49. Odoux C, Fohrer H, Hoppo T, Guzik L, Stolz DB, Lewis DW et al. A stochastic model for cancer stem cell origin in metastatic colon cancer. Cancer Res 2008; 68: 6932-6941.

50. Kwon HJ, Rhim JH, Jang IS, Kim GE, Park SC, Yeo EJ. Activation of AMP-activated protein kinase stimulates the nuclear localization of glyceraldehyde 3-phosphate dehydrogenase in human diploid fibroblasts. Exp Mol Med 2010; 42: 254-269.

Cell Death and Disease is an open-access journal published by Nature Publishing Group. This work is licensed under a Creative Commons Attribution 4.0 International Licence. The images or other third party material in this article are included in the article's Creative Commons licence, unless indicated otherwise in the credit line; if the material is not included under the Creative Commons licence, users will need to obtain permission from the licence holder to reproduce the material. To view a copy of this licence, visit http://creativecommons.org/licenses/by/4.0 